\title{
RECENT RESULTS OBTAINED FROM THE PRESERVA- TIVE TREATMENT OF TELEPHONE POLES
}

\author{
BY F. L. RHODES AND R. F. HOSFORD
}

\section{Abstract OF Paper}

The results of an experience with treated poles over a period of 18 years have been analyzed. Data are given for poles treated by pressure, open tank, and brush methods. The relation of these methods of treatment to the conditions which have determined the choice of pole timbers in the United States is outlined. The experience with brush treatments has reached a more advanced stage than that with the other types of treatment and is consequently discussed in greater detail. Rates of decay, increase in life by treatment, the effect of seasoning, and the characteristics of the damage to poles caused by decay and by insects, are all covered.

\section{INTRODUCTION}

$\mathrm{T}^{\mathrm{H}}$ HIS PAPER sets forth results that have been reached in the plant of the American Telephone and Telegraph Company and associated companies through the use of distillates of coal tar or of wood tar for the preservative treatment of wooden poles. The experience reported covers several typical processes for applying the preservative, which will serve to show the varied possibilities attainable through the choice of methods for applying the class of materials studied.

The methods employed for studying these typical processes have consisted mainly in the installation of experimental series of poles* to form parts of lines used for regular service. After exposure of these experimental groups of poles for a time sufficient to allow of the beginning of changes in their condition, they have been subjected to regular and systematic inspections. Except in the case of the experiments with creosoted pine, it has been the practise to include, in each experimental series, untreated poles in sufficient number to afford a definite basis for conclusions as to the effects of the preservative methods. Untreated pine was known to yield such a short life under the

\footnotetext{
* See Appendix A for bibliography of previous publications relating to this work.
} 
conditions to which creosoted pine poles were exposed that a comparative determination of its life would not possess any practical value.

The bulk of the pole supply in this country has been drawn from three varieties of timber; two species of cedar and one of chestnut. All of these timbers show considerable resistance to decay when exposed in contact with soils. Being available in sizes suited for pole construction in much larger quantities than other species which also possess this desirable characteristic, the market supply for many years has consisted mainly of these three species. As many other species possess all of the other characteristics desirable in a pole timber (such as strength, available quantity, etc.) and as cedar and chestnut are not so distributed as to be locally available in all sections of this country, it is, of course, often desired to know what can be done with species grown in the immediate neighborhood of lines to be built.

Southern pine is a timber available in large quantities in regions at a considerable distance from supplies of cedar or chestnut. In the territory to which it is native, it is neither durable in the ground nor above it. It possesses, however, in good measure, all of the other qualities desired in a pole timber. Timbers deficient in durability both in the ground and above it, require; necessarily, the application of preservative throughout their entire length. This requirement favors the use, for their treatment, of the cylinder pressure process. This process was one of the earliest of preservative processes to be established upon a commercial basis, and is today, the most prominent in the field with respect to number of plants and volume of business. Historically, the longest experience which we have to report was obtained with Southern pine treated by this process. The results obtained with these Southern pine poles, impregnated with creosote by the cylinder pressure process, will serve to illustrate the possibilities of what we shall hereafter refer to as whole length treatment.

We have already referred to durability, when exposed in the ground, as an important characteristic for a pole timber. It is the general experience that the part of the pole which is placed in the ground is the least durable section, even in the case of species which are ranked as the most durable pole timbers. In most soils, the section of the pole lying between a plane a few inches above and a plane one to two feet below 
the surface of the ground, which we shall hereafter term the ground line section, is found to suffer much more from decay than any other part of the pole. In a few soils, this region of maximum decay extends to greater depths in the ground; occasionally even to the butt end of the pole. An observation of the condition of the ground line section can, however, be depended upon, in the case of timbers of the relatively durable class, to show the deterioration of a pole due to decay, except as defects were originally present in other sections of the pole.

The first work devoted to retarding deterioration in the ground line section of poles made from durable species of timber consisted in applying preservative to the surface of this section with a brush. This process has been generally known as the brush treatment and it is fortunate that this name was early applied to it, as both its technique and its aims are different from those of the ordinary processes of painting. The brush treatment is an inexpensive process and requires no plant and but few tools for its application. Although the slight penetration of the preservative attainable by this process has always been recognized as limiting its effect in retarding decay when compared with processes forcing the preservative to enter deeply into the wood, its other characteristics have made it the most widely used of all pole treating processes. Three experimental series of poles located respectively in Georgia, northern New York, and Nebraska, will furnish data relating to this process.

The comparatively small gain in life anticipated from the brush treatment led, at the time when the experiments which we are to describe were begun, to the inclusion of poles treated by the open tank process. This process, while then new in its application to poles, had long been employed in some of its varied forms for treating other timber products. It has never been extensively employed for whole length treatment but possesses considerable advantages for part length treatments. When applied to the butt sections of cedar and chestnut poles it can be made to give a much greater penetration than the brush treatment. As penetration is generally agreed to be, to some extent, a measure of preservative efficiency, it was expected that the open tank treatment would show a greater increase in life than the brush treatment. Two experimental series, located in Northern New York and Nebraska, are reported on for this treatment, and it will be seen that the expectations of improvement over the brush treatment are being justified. 


\section{Whole Length Treatments}

Washington-Norfolk Line. This pole line of the American Telephone and Telegraph Company, extending from Washington, D.C., to Norfolk, Va., was built during the summer and fall of 1897. For some twenty miles south of Washington chestnut poles were used; for the rest of the line creosoted pine poles and guy stubs to the number of 9975 were installed. Most of the poles were sawn to fixed dimensions, 9555 being of square and 13 of octagonal cross-section. The remaining 407 pieces were natural round poles.

These poles were specified to be impregnated by the cylinder pressure process with not less than twelve pounds of dead oil of coal tar per cubic foot of timber. The treating operations were carefully and continuously inspected by company employees. Frequent tests were made of the dead oil of coal tar as the work of preparing these poles progressed.*

Representative short sections of the line were inspected in 1903, about 300 poles being examined. No appreciable impairment was found. In 1908, the first regular maintenance inspection of the line was made and 14 square and 3 round poles were removed on account of decay. The total removals for decay prior to 1908 amounted to 4 poles. On December 1, 1914 , the number of poles removed for decay had risen to 39 or about 0.4 per cent of the number originally installed. Table I gives in summary all pole changes occurring in the creosoted section of the Washington-Norfolk line and their causes.

In December 1914, the current condition of the creosoted poles was studied by making a thorough and detailed inspection of a little over 1600 poles. Sections of from 89 to 312 poles were chosen at different points throughout the line so as to secure representative data on its condition. Special care was taken to cover sections adjacent to previous removals for decay. The results of this inspection are set forth in Table II, where data relative to the soil conditions surrounding all poles inspected are given, as well as the results specifically bearing upon poles found to show signs of decay. In Table III, the results of this inspection are combined with the records of prior experience for the sections of line examined.

It will be noticed from Table II that the cause of deterioration for 36 of the 42 poles showing decay in the top section was the cutting off of the top. Signs that the top had been cut

\footnotetext{
*See Appendix B-Analyses of preservatives-for details.
} 


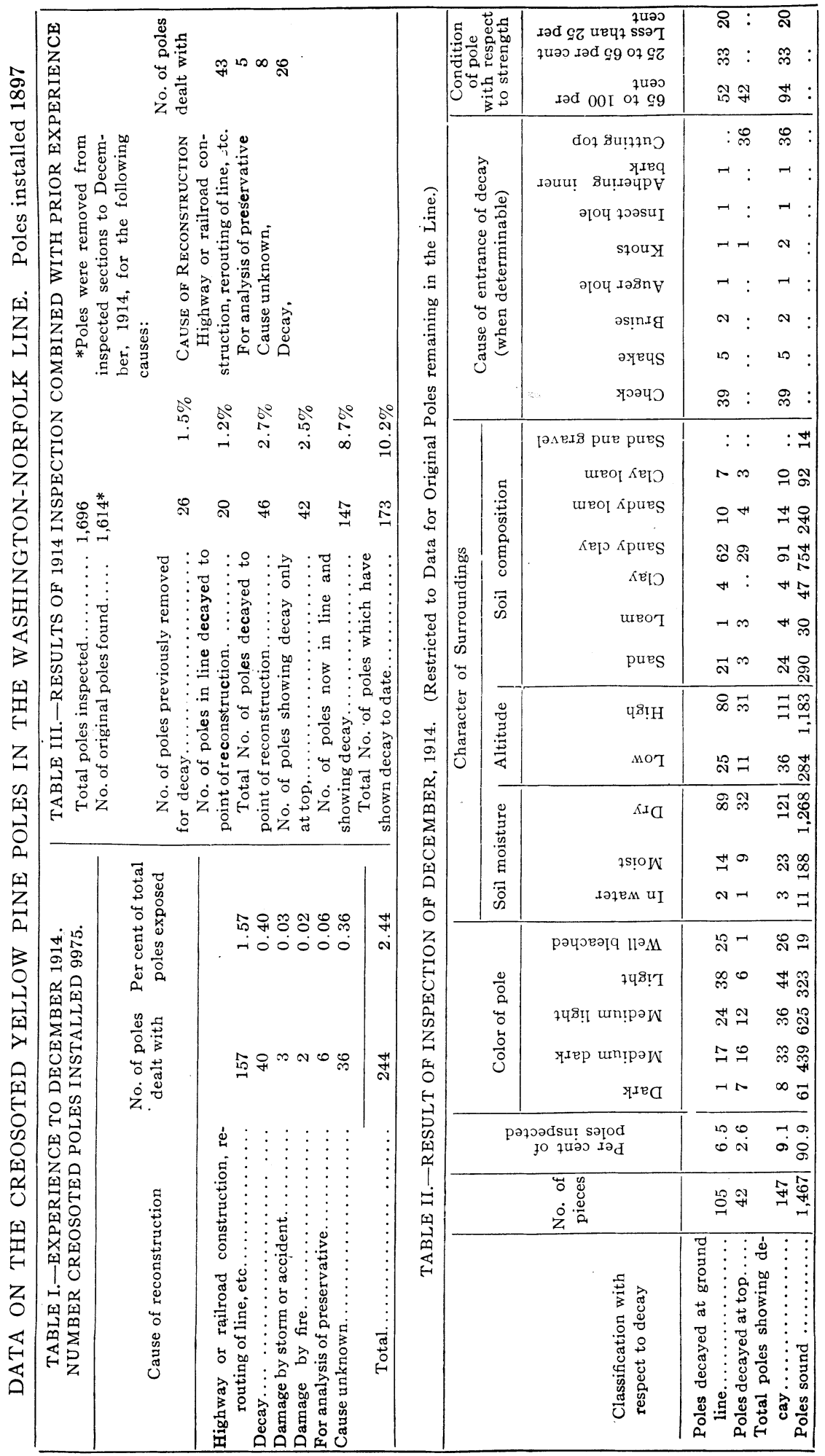


off were found on only 21 sound poles, so that cutting off the top after treatment caused deterioration on 62 per cent of the poles concerned. Decay in the top section has not as yet caused any great reduction in the strength of the poles as all show over 65 per cent of their original strength. These results serve to emphasize, however, the rule which is one of the axioms of good treating practise, viz., that all timber should be completely framed before treatment.

It will be seen that comparisons of the soil data relating to moisture, altitude, and proximate composition give no indication that any variation in these characteristics is favorable to decay. Perhaps this is because only relatively few poles have as yet become unsound, since some apparent effects of soil differences will be noticed in the pole line next to be discussed.

From the section of Table II summarizing the external appearance of the poles examined, it will be seen that the bleached and the other lighter colored poles yield a percentage of decayed specimens considerably above the average for all poles inspected. Sixty per cent of the poles showing decay in the ground line section are "light" or "well bleached " as against twenty-three per cent of the sound poles. Fifty-seven per cent of the poles classed as "well bleached" show signs of decay as against 1.5 per cent of the poles contained in the " dark " group at the other end of the color scale. Poles showing decay at the top have been omitted from these comparisons, as their deterioration is almost entirely due to the cause already discussed. The lighter colored poles are presumably those which retain the lesser amounts of preservative, so that their predominance with respect to decay suggests that life will increase with the amount of preservative applied.

Observations which it is not practicable to present in tabular form indicated that the predominant manner in which decay began in the poles of square cross-section consisted in an attack near the center of one side. The shaping of the poles exposed the heartwood in the central part of each side at the ground line section. Practically all the checking noticed was confined to this exposed heartwood. The combination of the tendency to check with the slighter penetration which can be obtained in heartwood would seem to account for the predominance of this form of decay.

Montgomery-New Orleans Line. This pole line of the American Telephone and Telegraph Company, extending from Mont- 
gomery, Ala., to New Orleans, La., was built in the summer and fall of 1899. From Montgomery to Hurricane, Ala., chestnut and juniper poles were installed. Between Hurricane and New Orleans creosoted round yellow pine poles were used in its construction, a total of 7644 pieces being placed. The nature of the country traversed made it necessary to install an unusually large proportion of these in the form of $A, H$ and tripod fixtures.

All poles were specified to be impregnated by the cylinder pressure process with not less than twelve pounds of dead oil of coal tar per cubic foot of timber. The treating operations were carefully and continously inspected by company employees. Frequent tests* were made of the dead oil of coal tar as the work of preparing these poles progressed.

Representative sections of the line were inspected in 1906 , some 2152 pieces being examined. Each pole, stub, brace or pile employed as part of a fixture was inspected as a separate piece as a considerable number of the different types of fixtures referred to above were encountered in the sections covered. The results of this inspection are summarized in Table IV.

A second inspection of the line was made early in 1915 . The detailed records of the 1906 inspection were not available so that a new choice of sections representative of the line had to be made. It is known that part of the poles examined were also examined in 1906 but it is not possible to compare their condition at the two periods.

The pole changes occurring in the creosoted section of the Montgomery-New Orleans line, up to the time when the last inspection was begun, are set forth in Table V. The causes for the changes are also given in this table. It will be noticed that removals made on account of decay amounted to only 0.3 per cent of the poles installed, although it must be noted that some of the poles included in the group whose cause of removal is unknown were probably removed on account of decay.

Table VI gives in summary the results obtained in the inspection of 1915. Nine sections of line were examined in the 1915 inspection. These sections were chosen so as to be representative of the different types of country through which the line passes. The number of pieces included in a section ranged from 150 to 228 . In Table VII the results of the 1915 inspection are combined with the records of prior experience for the sec-

* See Appendix B-Analysis of Preservatives. 
tions of line examined. It will be noticed that the data indicate that in 1906, seven years after the line was built, about one per cent of the. poles had deteriorated to an extent calling for reconstruction. In 1915 , about $15 \frac{1}{2}$ years after the line was completed, the number of poles which had reached a point requiring reconstruction was probably about 5 per cent of the number installed. A little over 7 per cent of the poles showed signs of deterioration in 1906, while in 1915, the percentage showing signs of deterioration had risen to 33 .

It will be seen from comparisons of the soil data relating to moisture, altitude, and proximate composition, that the surroundings of the poles had some influence upon the beginning of decay. The proportion of decayed poles located in soils classed as dry is above the average. The difference in altitude along the route followed by this line is not great but it will be noticed that the locations classed as high had more than the normal proportion of decayed poles. Corresponding to these two indications it will be found from the data relating to soil composition that the lowest proportion of decayed poles was located in muck, which would necessarily be found in low, moist situations, whereas clay and loam, which would be found mainly in the higher and drier locations, show more than average percentages of decayed poles.

From the section of Table VI, summarizing the external appearance of the poles, it will be seen that the bleached and other lighter colored poles yield a percentage of decayed specimens considerably above the average for all poles inspected. For example, 57 per cent of the poles classified as "well bleached" were found to be decayed, as against 13 per cent of the poles classed as "dark."

The condition of the pole with respect to adhering tar also was found to offer distinctions in resistance to decay. Fifty-six per cent of the poles showing no tar were decayed, as against 30 per cent decayed among poles showing streaks of tar near the ground line, and 18 per cent decayed for poles streaked with tar throughout their length.

The lighter colored poles, and the poles carrying little or no tar, are presumably those which originally contained less than the average amount of preservative so that their greater tendency to decay reinforces the conclusion that life will increase with the amount of preservative applied.

The cause for the entrance of decay was recorded in the case 
of poles which had not deteriorated to an extent sufficient to render such a determination impossible. It will be seen from the data relating to this subject, summarized in Table VI, that " checks" and "shakes" were the only important causes for the entrance of decay noted.

It will be noticed that insects were present in a considerable proportion of the decayed poles. White ants (termites) were found in 48 per cent of the poles injured by decay and in practically every case this insect contributed to the injury. Round headed borers were found in about 10 per cent of the poles. These insects also are responsible for some injury to poles. The other insect forms reported do not seem to be responsible for any damage to the pole but probably entered the pole after decay had made cavities in the wood. Whether the white ants and the round headed borers produced the initial injury to the pole structure in any case was not determinable. Large checks were noted in 5 per cent of the sound poles and 30 per cent of the decayed poles. Forty per cent of the poles attacked by white ants contained large checks. This would suggest that the entrance of the white ants was to some extent aided by breaks in the external layers of impregnated wood but we have not as yet been able to reach any conclusive determination upon this point.

Retention of Preservative by Poles. Evidence has already been brought out in discussing the results of inspections of creosoted pole lines indicating that the tendency of the creosoted pole to decay is dependent to some extent upon the quantity of preservative which it contains. Creosoted poles have to be prepared in large batches. The amount of oil used for impregnating a cylinder charge is readily determinable but such a determination affords no means for ascertaining whether all of the poles treated at the same time receive equal shares of the preservative. Measurements of penetration upon individual poles are of some assistance in bringing the minimum impregnation nearer to the average, but the variations in the thickness of the sapwood layer in the different trees interferes with a requirement for uniform depth of penetration. Since some control can be exercised over the impregnation of the individual pole, and since there is some reason to believe that the presence of at least a minimum amount of preservative is needed for the prevention of decay, information bearing on the retention of the preservative by poles in service possesses much practical interest. Changes 
which the oil used for impregnating a pole undergoes during the period of service also have an important bearing upon the choice of preservatives.

It has been found possible to extract dead oil of coal tar from treated timber without appreciable contamination from the resins and oily substances which may be present as normal constituents of the wood. Several of the creosoted poles in the two lines just discussed have been subjected to this extraction process. The composition of the extract obtained has been studied in all cases and in some of the cases determinations have also been made of the amount of extract obtained from unit volumes of the timber. The results of this work are summarized in Table VIII.

It will be seen that extractions of preservative have been made both from the top and the butt sections of poles. The top of the pole is exposed to the action of sun, air, and rain. The action of gravity also tends to produce movement of the preservative towards the butt of the pole. The butt end of the pole, being surrounded by the soil, is much less subject to loss by evaporation, since the direct access of air to it is slight and heating through direct exposure to the sun is eliminated. Some evaporation can probably occur through porous soil and some through the vessels of the pole timber. The removal of any soluble constituents of the preservative is, of course, facilitated by the exposure of the butt to ground water.

Examination of the table of analyses will show that the conditions to which the top of the pole is exposed cause a more rapid removal of the volatile constituents of the preservative than occurs in the butt section. Analytical data showing the composition of the oil with which a particular pole was impregnated are not available but the average results of all tests made on oil used for treating the poles in the WashingtonNorfolk and the Mongtomery-New Urleans lines are given in Appendix "A." It will be seen by comparing the average results with the individual data of Table 8 that the poles have suffered losses in the proportion of low boiling constituents.

The data indicate that no appreciable loss by evaporation occurs in the case of constituents of the oil distilling above 270 deg. cent. Such cases as pole No. 10,272 of the Montgomery-New Orleans line, which shows the least amount of preservative in the top section of the pole, with increasing 


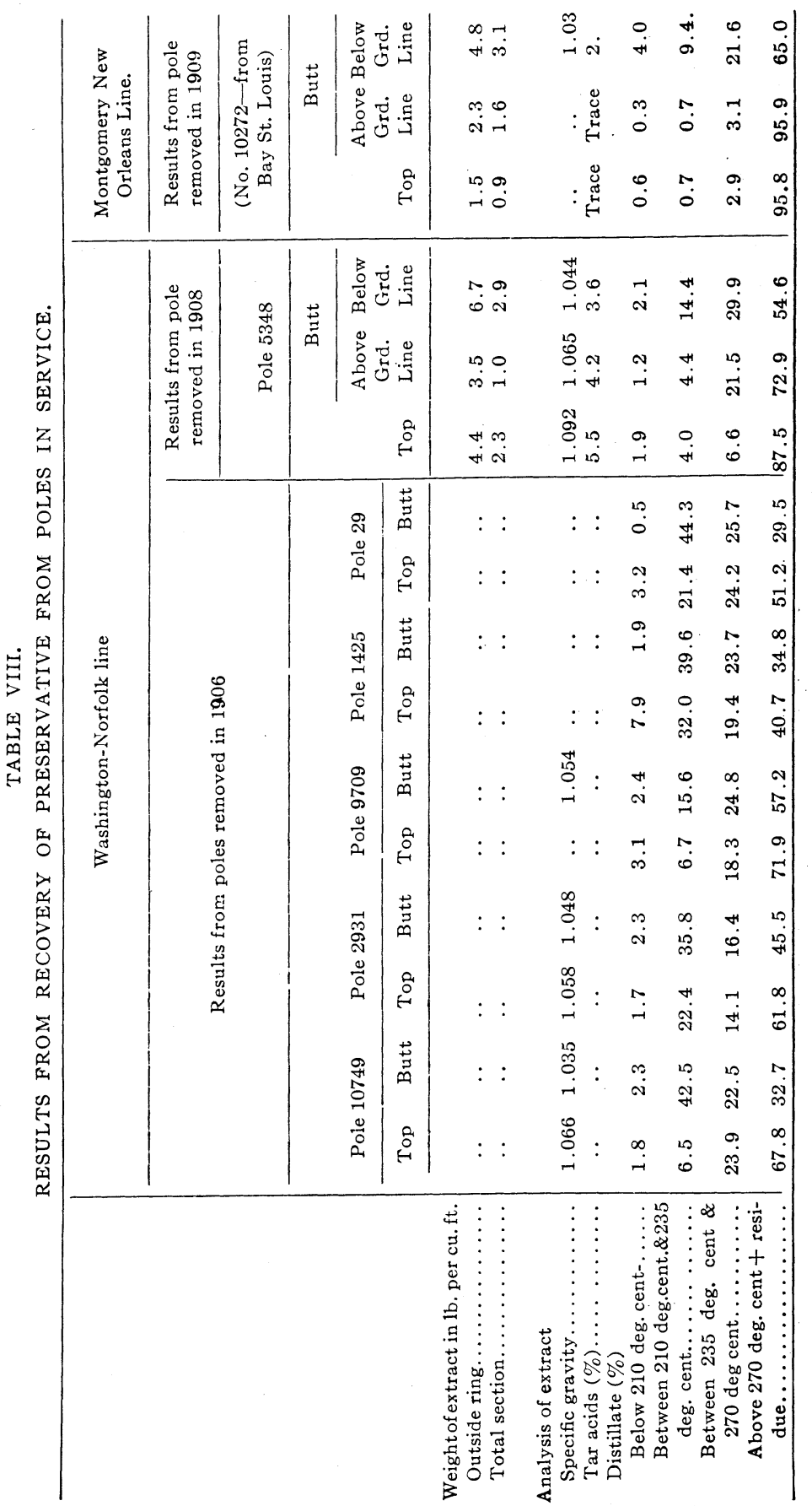


amounts as sections are examined nearer to the butt end of the pole, illustrate the effect of gravity in removing preservatives from the upper parts of the pole. This pole No. 10,272, it may be noted, was exposed in a warmer climate than the other poles reported upon and the minute percentages of low boiling constituents remaining in the sections above the ground line undoubtedly are a consequence of the temperatures to which it was exposed. The retarding effects exercised by envelopment with soil upon the evaporation of preservative are well illustrated in the case of the section of this pole taken from below the ground line, which contained substantial amounts of oil boiling below $270 \mathrm{deg}$. cent.

It will be noticed that the section of pole No. 5348 of the Washington-Norfolk line taken from just above the ground line shows a smaller quantity of preservative extracted than was obtained from the top section. This pole was removed on account of decay which had entered at one side in the ground line section and had destroyed practically all of the untreated central portions of the pole when it was removed from service, The decayed section had a sound treated shell near the point where decay entered which was much thinner than the shell on the opposite side of the pole. It seems probable that this ground line section was deficient in impregnation and that the irregularities noticed in the analytical results are a consequence of this deficiency.

As indicated in TableVIII, the first poles subjected to extraction were removed from the line in 1906 . These pole samples were divided among several laboratories. Dr. Von Schrenk* published the results of his work upon these samples in the following year. The results obtained with these poles, together with other work of a similar nature brought out at the same time. have since exercised a strong influence upon developments relating to the choice of preservatives.

\section{Butt Treatments}

The investigations relating to butt treated poles which we shall describe, have been carried on in cooperation with the United States Forest Service. The numerous publications relating to this work listed in Appendix A illustrate the great care and attention which the Forest Service has given to these projects. The development of the open tank treatment for poles

\footnotetext{
* See Appendix A-Bibliography-for reference.
} 
is probably the most prominent contribution from the Forest Service, but the preparation of all poles for the experiments was also carried on by its representatives and the attention which was given to details in this work has been found to be of the greatest value.

The Brush Treatment. The first use of the brush treatment in telephone construction and, so far as our information goes, the first application to poles, was made by the Colorado Telephone Company. In June, 1899, a 30-ft. Michigan cedar pole line was built between Denver and Boulder. Four hundred and twenty of the poles used in this line were treated with carbolineum; the oil being heated to temperatures of from $120 \mathrm{deg}$. to $150 \mathrm{deg}$. fahr., and applied to the butts of the poles with a wide brush. With the treated poles, an approximately equal number of untreated poles was installed, each of these two classes being set alternately in groups of five.

The country through which this line passes is rough; the soil is composed of "gumbo," black clay, rock and sand; part of the line is located in swampy ground. In August, 1903, an inspection was made of representative sections of the line. It was found that the poles which had been treated were sound, while the poles which had not been treated were found to have decayed to a depth of from $\frac{1}{2}$ of an inch to $1 \frac{1}{2}$ inches. Subsequent inspections made of this line have confirmed the conclusion, drawn after the first inspection, to the effect that the brush treatment was successful in preserving the poles. Experience with other lines, built shortly after, upon which the brush treatment was used, developed the very important conclusion that success with the brush treatment could only be expected when it was applied to seasoned poles.

In applying a brush treatment, that part of the surface of the pole which it is desired to protect by the preservative should first be thoroughly cleaned. All dirt, adhering inner bark, soft or decayed timber, etc., should be cleared away. The pole should be seasoned before it is attempted to apply the treatment and the surface which it is desired to treat should be dry. The preservative is applied to the cleaned surface by means of a brush, preferably one with a long handle. The application is most conveniently carried out when the pole is placed so that it can be rotated while the preservative is applied to the upper segments of its surface. The pole is turned until the entire surface has been coated. As the aim of the process is to im. 
pregnate the timber, the surface which is being brushed should be kept flooded with the preservative and care should be taken to cause the preservative to enter all cracks, checks, knot holes, etc. The best results will be obtained by applying a second coat of preservative after the first coat has had time to work its way into the wood. Although some preservatives will give fair penetration when applied cold, the best results with any preservative are undoubtedly obtained when it is heated before application, preferably to from $150 \mathrm{deg}$. to $200 \mathrm{deg}$. fahr.

The extent of the surface to which the treatment is applied can best be determined after consideration of the characteristics of the soils in which the treated pole may be placed. It does not seem to be necessary to carry the treatment from a point above the ground line all the way to the lower end of a pole except in cases where heavy decay takes place near the butts of untreated poles as well as in the ground line section. For the usual case of heavy decay concentrated at the ground line section, a treatment extending from one foot above the ground line to two feet below it should be sufficient. Most of the poles to be reported upon were treated from a point two feet above the butt of the pole to a point eight feet above the butt. The cedar poles locally treated in Nebraska and placed in the OmahaDenver line were, however, only treated in the ground line section, i.e., from about one foot above the ground line to about two feet below it.

The Open Tank Treatment. When plans are being made for the experiments with poles whose results we are about to describe, much thought was given to methods which could be used as an alternative to brush treatments. Several methods were given a preliminary trial but the only one which was found to be practicable was that to which the name of the open tank treatment has been given. Various timber parts had previously been treated by immersion in hot or cold preservative but the first application of this type of process for treating the butts of poles appears to have occurred in the case of these experiments.

The process consisted in immersing the butt ends of the poles to be treated in the hot preservative and keeping them immersed until the bubbling, caused by air or water escaping from the pole, ceased. The hot oil was then allowed to cool and the vacuum created in the cells of the pole timber in the course of the heating assisted in drawing oil into the wood. In the earlier work with this process, 24 hours was occupied in dealing with a 
charge of poles, the heat being kept up during the greater part of the working day. The oil was allowed to cool over night and the poles withdrawn from the bath the next morning. In the later work, particularly in the case of chestnut poles treated at Parkton, Md., the possibility of shortening the period of heating was studied and a considerable reduction in the total time required for treatment attained.

The open tank treatment causes a substantially greater penetration of the preservative into the wood than does the brush treatment. Measurements of penetration upon "open tank" poles show a range in depth of penetration from $\frac{1}{4}$ of an inch to $\frac{1}{2}$ of an inch or more, while penetration with the brush treatment may range from-a little over $1 / 16$ of an inch to somewhat under $\frac{1}{4}$ of an inch. The open tank treatment uses much larger quantities of preservative per pole than the brush treatment, as will be seen from the data assembled in the tables relating to poles handled under these two processes. This increase in the quantity of preservative absorbed is due to the greater depth of penetration and to the greater length of pole butt treated.

Distribution and Location of Experimental Series. Three independent series of poles have been installed in order to secure an experimental determination of the effect of butt treatments. The first series was located in the Savannah-Meldrim line of the Southern Bell Telephone and Telegraph Company. The installation of the poles was completed in the summer of 1905 . The experimental poles are located just west of Savannah in the relatively low land which reaches back from the seacoast border of the State of Georgia. This location was known to be one in which untreated poles decayed at a relatively rapid rate. It was selected with a view to obtaining a severe test of the experimental treatments and with the hope that conclusive results as to their efficiency could be obtained in a relatively short time.

The second series of poles was installed in the late summer and fall of 1905 in the Buffalo-Warren line of the American Telephone and Telegraph Company. The experimental poles were placed in a section of this line lying between Gowanda, N.Y., and Warren, Pa. About two-thirds of the poles are north and one-third south of Jamestown, N. Y. The experimental poles are located in a rolling country. The settings are well distributed between hill and valley surroundings. The hills 
grow higher and more precipitous as the southern end of the section is approached. This location was chosen so as to give evidence as to the behavior of treated poles in the northern part of this country. It was not expected that deterioration would be as rapid as in the Savannah-Meldrim line and experience has justified this expectation.

The third experimental series was placed in the OmahaDenver line of the American Telephone and Telegraph Company. Most of the experimental poles were located between Ashland and Lincoln, Neb., but one group of about 300 poles was placed considerably west of this section near North Platte, Neb. The country in which this series is located is relatively level with moderate undulations, gradually rising in altitude towards the West. The line was built in 1910. Of the three lots of experimental poles placed, one had been prepared late in 1906 and another early in 1907. As these poles had to be held for three years before a location could be secured, it was thought that changes might have occurred during the period of storage which would tend to increase their rate of deterioration. Several hundred cedar poles were, therefore, brush treated under carefully observed conditions at the time the line was built and set in groups with untreated cedar poles so as to afford a check upon the behavior of the treated poles which had been kept in storage.

Preservatives Used. The preservatives used in all brush and open tank treatments reported upon were distillates of either coal tar or wood tar. Six of the preservatives used were proprietary compounds sold commercially under trade names. These six preservatives have been given letter designations and will be referred to by these letters throughout this paper.

The only other preservative used was dead oil of coal tar. As will be seen from the analyses of this material which we give, the dead oil used in the experimental work was a good representative of the product ordinarily obtainable for creosoting treatments in the market at the time the experiments were started. Since then a tendency has arisen for giving preference to dead oils containing less low-boiling constituents. In consequence of this change in opinion the dead oil which was used would today be regarded as a little below the standard grade.

The six proprietary preservatives and the dead oil of coal tar were each used independently for brush treating experimental poles. Only dead oil of coal tar was used in preparing 
the open tank treated poles. The much greater quantity of preservative needed for the open tank treatment makes the employment of a low-priced preservative desirable and the dead oil of coal tar was distinctly lower in price than any of the other preservatives experimented with.

Analyses were made of all of the preservatives experimented with. These analyses have been collected and are given in detail in an appendix.*

Experience with Coal Tar. In addition to the experiments outlined above, treatments with undistilled coal tar and undistilled pine tar were also applied to a number of poles included in the Savannah-Meldrim and the Buffalo-Warren series. The tar was heated and applied to the pole by a brush just prior to setting. No appreciable penetration into. the wood was obtained. The tar formed a substantial superficial coating which, in most cases, still appeared to be in good condition when the first inspections of the experimental poles were made four to five years after their setting. It was found, however, that this superficial coating was ineffective in preventing decay so that the tar coated poles had deteriorated practically to the same extent as adjacent untreated poles. This experience indicates clearly the ineffectiveness of a tar coating from a preservative standpoint and no further reference to the tar coated poles reported upon in the tables of results will be made in the discussions to follow.

Savannah-Meldrim Line. The experimental series placed in the Savannah-Meldrim line included approximately equal numbers of juniper (chamaecyparis thyoides) and of chestnut (castanea dentata) poles. The juniper poles were collected at Wilmington, N. C., for seasoning and treatment. The chestnut poles were collected at Mt. Pisgah, N. C., for similar work.

Brush treatment was the only method of preservation employed in preparing the treated poles in this line. All of the brush treated poles had been seasoned prior to their treatment. Half of the poles included in the experimental series were untreated and were set for the purpose of giving direct comparisons with the treated poles. A little more than half of the untreated poles were seasoned; the remainder were green when set.

Treated and untreated poles of the same species were placed alternately in the line. The exact order of setting is shown in

\footnotetext{
*See Appendix B-Analyses of Preservatives.
} 
detail in Table IX. The poles were classified so that the seasoned poles contained in each sub-series of 34 , such as is shown in Table IX, had been subjected to seasoning for the same length of time. There were $12 \mathrm{sub}$-series of juniper poles and 12 sub-series of chestnut poles.

TABLE IX.

\begin{tabular}{|c|c|c|c|}
\hline $\begin{array}{l}\text { No. of } \\
\text { pole }\end{array}$ & $\begin{array}{l}\text { Condition } \\
\text { when set }\end{array}$ & Preservative applied & $\begin{array}{l}\text { Method of } \\
\text { treatment }\end{array}$ \\
\hline $\begin{array}{r}1 \\
2 \\
3 \\
4 \\
5 \\
6 \\
7 \\
8 \\
9 \\
10 \\
11 \\
12 \\
13 \\
14 \\
15 \\
16 \\
17 \\
18 \\
19 \\
20 \\
21 \\
22 \\
23 \\
24 \\
25 \\
26 \\
27 \\
28 \\
29 \\
30 \\
31 \\
32 \\
33 \\
34\end{array}$ & $\begin{array}{l}\text { Seasoned } \\
\text { Seasoned } \\
\text { Seasoned } \\
\text { Green } \\
\text { Seasoned } \\
\text { Seasoned } \\
\text { Seasoned } \\
\text { Green } \\
\text { Seasoned } \\
\text { Seasoned } \\
\text { Seasoned } \\
\text { Green } \\
\text { Seasoned } \\
\text { Seasoned } \\
\text { Seasoned } \\
\text { Green } \\
\text { Seasoned } \\
\text { Seasoned } \\
\text { Seasoned } \\
\text { Green } \\
\text { Seasoned } \\
\text { Seasoned } \\
\text { Seasoned } \\
\text { Green } \\
\text { Seasoned } \\
\text { Seasoned } \\
\text { Seasoned } \\
\text { Green } \\
\text { Seasoned } \\
\text { Seasoned } \\
\text { Seasoned } \\
\text { Green } \\
\text { Green } \\
\text { Seasoned }\end{array}$ & 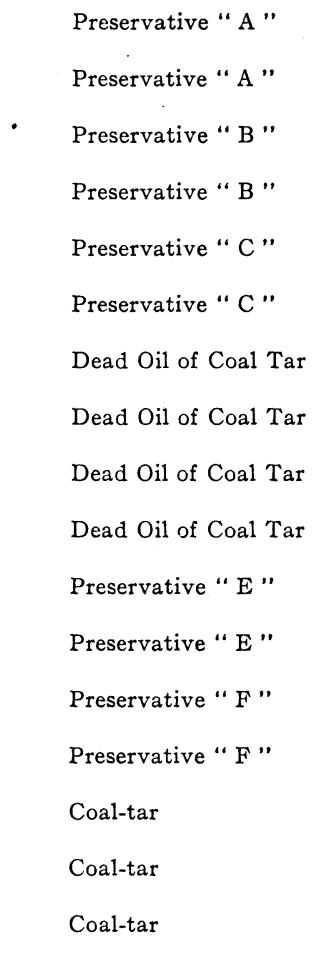 & $\begin{array}{l}\text { Brush } \\
\text { Untreated } \\
\text { Brush } \\
\text { Untreated } \\
\text { Brush } \\
\text { Untreated } \\
\text { Brush } \\
\text { Untreated } \\
\text { Brush } \\
\text { Untreated } \\
\text { Brush } \\
\text { Untreated } \\
\text { Brush } \\
\text { Untreated } \\
\text { Brush } \\
\text { Untreated } \\
\text { Brush } \\
\text { Untreated } \\
\text { Brush } \\
\text { Untreated } \\
\text { Brush } \\
\text { Untreated } \\
\text { Brush } \\
\text { Untreated } \\
\text { Brush } \\
\text { Untreated } \\
\text { Brush } \\
\text { Untreated } \\
\text { Brush } \\
\text { Untreated } \\
\text { Brush } \\
\text { Untreated } \\
\text { Brush } \\
\text { Untreated }\end{array}$ \\
\hline
\end{tabular}

Note: The above series was repeated 24 times, series No. 2 beginning with pole No. 35, series No. 3 with pole No. 69 , etc.

Several of the poles prepared for the experiment were injured in the course of transportation or setting. Several other poles to which it was intended to apply treatment failed to receive it on account of the supply of some of the preservatives running short. In consequence of this, it will be seen on examining Table 
$\mathrm{X}$, which gives the experimental data secured from the Savannah-Meldrim line, that there were slight deviations from the arrangement indicated by Table IX.

Four inspections have been made to determine the condition of the experimental poles in the Savannah-Meldrim line. The first inspection was made in May 1909, about four years after the poles had been placed. The second inspection was made in November 1910; the third inspection in February 1912; and the fourth inspection in November 1913. In inspecting poles the earth was dug away to expose the ground line section for a depth of nearly two feet. The condition of the section was then carefully determined. Poles which showed no signs of deterioration or decay were classified as "sound." As was to be expected, the application of this designation was practically restricted to treated poles. Poles showing signs of deterioration or decay were carefully examined to determine the extent of the change. All soft and decayed matter which would interfere with the determination of the ground line circumference of sound wood was removed and the circumference then measured. All "pockets" of decay, whether external or internal in location, were carefully explored and measured, so that a proper reduction factor could be applied to the measured ground line circumference in order to obtain the ground line circumference equivalent to the amount of sound wood remaining in the pole.

During the course of each inspection special attention was given to the condition of any poles showing substantial deterioration with a view to determining whether they had fallen below the standard established for the maintenance of the line. Careful record was kept of all poles which were found to have fallen below the standard of maintenance, and of the methods selected by the Southern Bell Telephone and Telegraph Company for the reconstruction of these poles, whether by resetting, reinforcement or replacement. Record was also kept of any of the experimental poles undergoing reconstruction between inspections and of the cause for the line change. Where reconstruction has occurred due to other causes than deterioration by decay allowance for the fact has been made in the summarizing of the data.

Table $\mathrm{X}$ sets forth in summarized form the data relating to individual poles accumulated in these inspections. The table includes data relating to the seasoning and the treatment 
of the poles and the results of each inspection with respect to soundness, changes in circumference of good wood, and reconstruction work. It will be seen that by the time of the first inspection four years after the date of setting, decay had set in in the case of practically all untreated poles but that only a moderate proportion of the treated poles had at that time been affected by decay. The percentage of treated poles remaining sound decreased with each subsequent inspection, so that at the time of the last inspection in 1913 about 20 per cent of the juniper poles and about 40 per cent of the chestnut poles were still free from decay.

The changes in the circumference of sound wood are set forth in considerable detail. Where a large part of the poles which were subjected to any particular method of preservation are still sound, the average decrease in circumference for the group will necessarily be comparatively small because the divisor includes a large number of units which have not contributed to the decrease. Average changes in circumference for poles which showed decay are, therefore, given. Under the severe conditions of exposure which characterize this line, the decay of a pole which is at or near the end of its serviceable life, is liable to proceed rapidly. Because of this, it has been found desirable to give also the average decrease in circumference computed with the poles designated for reconstruction eliminated from the divisor. The table also gives the average decrease in circumference between inspections for poles showing decay at earlier inspections, and the maximum and minimum decrease in circumference recorded at each inspection, for the poles subjected to each particular treatment.

The last group of data included in the table shows the number of units subjected to reconstruction on account of deterioration by decay up to the end of each inspection. The figures given here include not only the poles designated for reconstruction on account of the results of the inspection but also any poles which may have been reconstructed either directly on account of decay between inspections or which were decayed to such an extent at the previous inspection that their reconstruction for that cause after the following inspection was certain although the nominal cause of removal may not have been given as decay. It will be noticed that over 80 per cent of the untreated juniper poles had been reconstructed by 1913 , as against about 30 per cent of the treated poles. About 30 per cent of the untreated, 
and a little over 10 per cent of the treated chestnut poles have undergone reconstruction.

Buffalo-Warren Line. The experimental series placed in the Buffalo-Warren line was made up wholly of chestnut poles. These poles had been prepared in two groups. One group was collected at Thorndale and Paoli, Pa.; the other at Dover and Mt. Arlington, N. J.

The Thorndale-Paoli group consisted of equal numbers of treated and untreated poles. About one-third of the treated poles had been subjected to the open tank process. Fourfifths of the open tank poles had been seasoned prior to treatment; one-fifth were treated in the "green" state. About two-thirds of the treated poles had been given a brush treatment; all of these poles had previously been seasoned. When this group was installed, treated and untreated poles were placed alternately in the line. The exact order of setting is shown in Table XI, which covers a sub-series of 34 poles. There were 24 such sub-series in the group. No attention was given to period of seasoning in arranging the poles for setting.

The Dover-Mt. Arlington group consisted of about threefifths treated and two-fifths untreated poles. A little less than one-third of the treated poles were prepared by the open tank process; all but one of these had been seasoned before treatment. The other treated poles had received a brush treatment after seasoning. Nearly all of the untreated poles had been seasoned. These poles were not set in any regular order and were scattered in groups of irregular size among untreated poles brought from other sources.

Two inspections have been made to determine the condition of the experimental poles in the Buffalo-Warren line. The first was made in September, 1910, about five years after the line was built. The second inspection was made three years later, in September, 1913. The methods of inspection employed have already been described in connection with the SavannahMeldrim line.

Table XII sets forth in summarized form the data relating to individual poles accumulated in these inspections. No poles have decayed to an extent necessitating reconstruction. The tables therefore show only the proportion of sound specimens noted and the magnitude of the circumference changes. Summarized data bearing on the seasoning and treatment of the poles are also included. 
It will be noticed that while decay had begun on practically all untreated poles when the first inspection was made, the decreases in circumference average much lower than in the Savannah-Meldrim line. The number of brush-treated poles

TABLE XI.

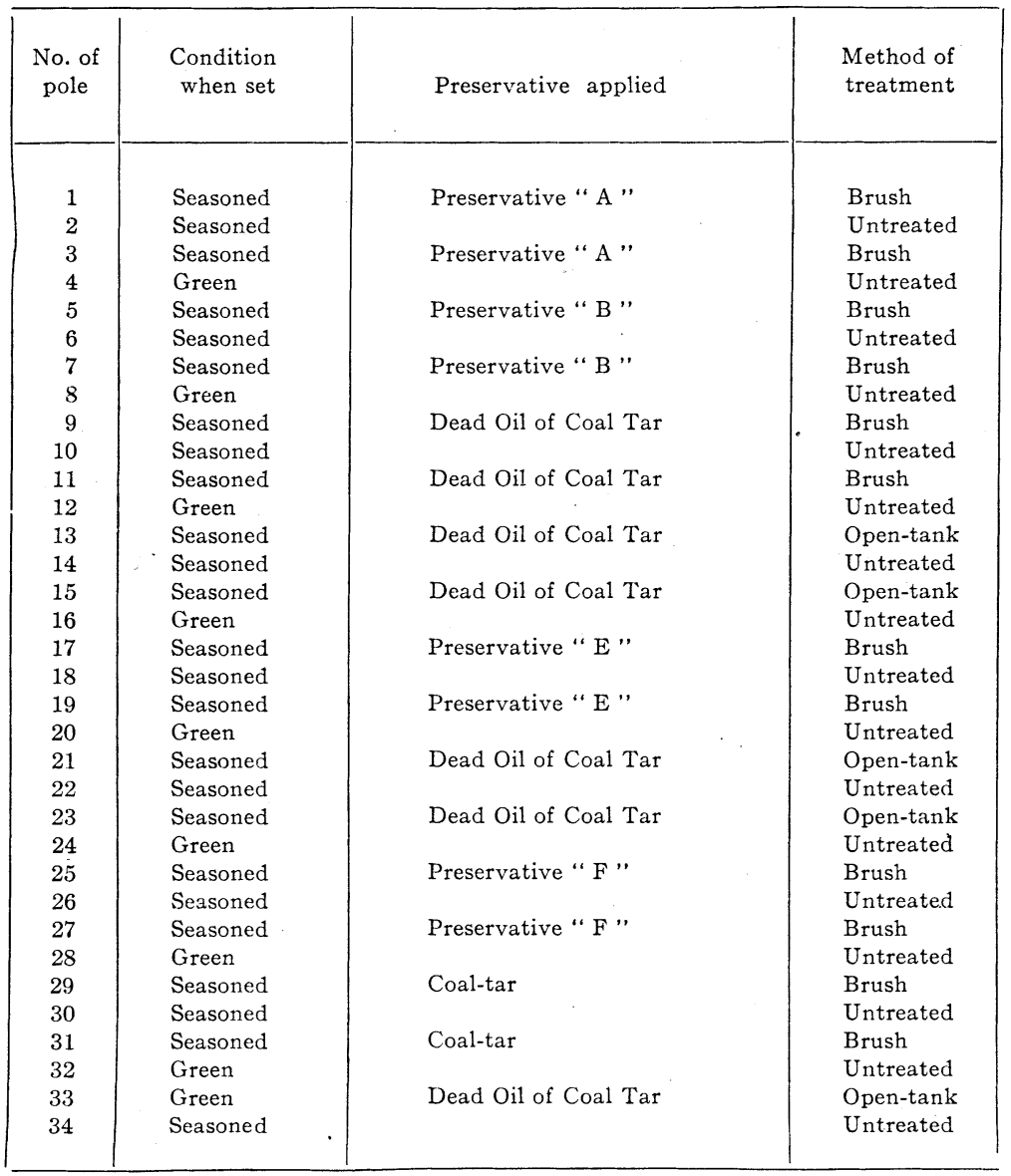

Note: The above series was repeated 24 times, series No. 2 beginning with pole No. 35 , series No. 3 with pole No. 69 , etc.

remaining sound in 1913 is a little less than 50 per cent of the total number installed. Only slight changes in the condition of the open tank treated poles installed have been noted and only a little over one per cent of the poles show these changes in condition. 
Omaha-Denver Line. The plans for the service tests of butt treated poles included, in addition to the series placed in the two lines already described, two other experimental groups which were to be prepared independently. Four hundred and sixty-five Eastern white cedar (thuya occidentalis) poles were collected at Escanaba, Mich., and held for seasoning until the latter part of 1906. Approximately three-fifths of the poles were then treated, about one-third being subjected to the open tank treatment and the remaining two-thirds being about equally divided for brush treatment by two different preservatives.

Five hundred and forty-two chestnut poles were at the same time being collected at Parkton, Md. After the process of seasoning had been studied with these poles one-third were given an open tank treatment and another third a brush treatment, two different preservatives being employed in this latter case.

Both the Escanaba and the Parkton poles were finished at a time when an opportunity of placing an experimental group of poles consecutively in line could not easily be found. The two lots of poles were held for three years awaiting a suitable occasion for their installation. When plans were completed for setting them in 1910 it was felt that the long period of holding might have produced changes affecting the efficiency of their preservative treatments. As the plans for building the Omaha-Denver line of the American Telephone and Telegraph Company, in which these two experimental groups were to be used, called for the brush treatment of several thousand Eastern white cedar poles, the construction work was arranged so that the brush treatment of several hundred poles was carried out under observed conditions. Dead oil of coal tar was applied to about half of the poles thus treated and a high-boiling distillate of coal gas tar (preservative A ) was applied to the remainder. Untreated poles were set aside in sufficient number to permit of setting one untreated pole for each two brush treated poles of this third experimental group. The poles included in this group had all been held in storage for a long time and were consequently well seasoned.

The Parkton poles were set near the eastern end of the new construction. The Escanaba poles were placed next in the line and next to them about two-thirds of the experimental lot prepared at the time of building the line. No exact order was 
followed in placing the Parkton and the Escanaba poles but a reasonably uniform distribution of the three types of treatment and of the untreated poles was attained. About half of the freshly treated poles were so installed as to give uniform series with each of the three methods of preparation grouped independently of the others. The other half of the poles were set so that an untreated pole alternated between each of the two types of brush treated poles. About 300 poles of the 1910 experimental group were given a location some 200 miles west of the other experimental poles near North Platte, Neb. These poles were set so as to bring an untreated pole between each of the two kinds of brush treated pole.

The installation of these experimental poles was completed in 1910. The first inspection to determine condition was made in 1914 after four years' exposure. The results of this inspection are given in Table XIII.

It will be noticed that nearly all of the poles subjected to the open tank treatment show no change in condition. The brush treated poles show relatively much greater percentages affected by decay than was the case with corresponding treatments in either of the other two lines reported upon. The greaterproportion ofdecay with the poles brush-treated with dead oil of coal tar included in the groups treated at Parkton and Escanaba probably has some connection with the relative volatilities of dead oil of coal tar and of preservative A. The dead oil of coal tar contains a substantially greater proportion of low boiling constituents than preservative A so that with the exposure of the treated poles to the sun and air for three years a considerable reduction in the amount of preservative retained by the pole may well have occurred. A rather severe tendency to checking was also noticed which is particularly marked in the case of some of the chestnut poles from Parkton. Poles which have reached the limit of air seasoning still retain large percentagès of moisture in their interior sections. It is possible that this internal moisture began to evaporate in the relatively dry climate of Nebraska and this evaporation may be the cause of the heavy checking.

Better results in the way of preservation were obtained in the case of the poles treated when the line was built. Here there is very little distinction between the results obtained with the two kinds of preservative used. It is to be noted that the poles treated had been held for rather long periods and were 


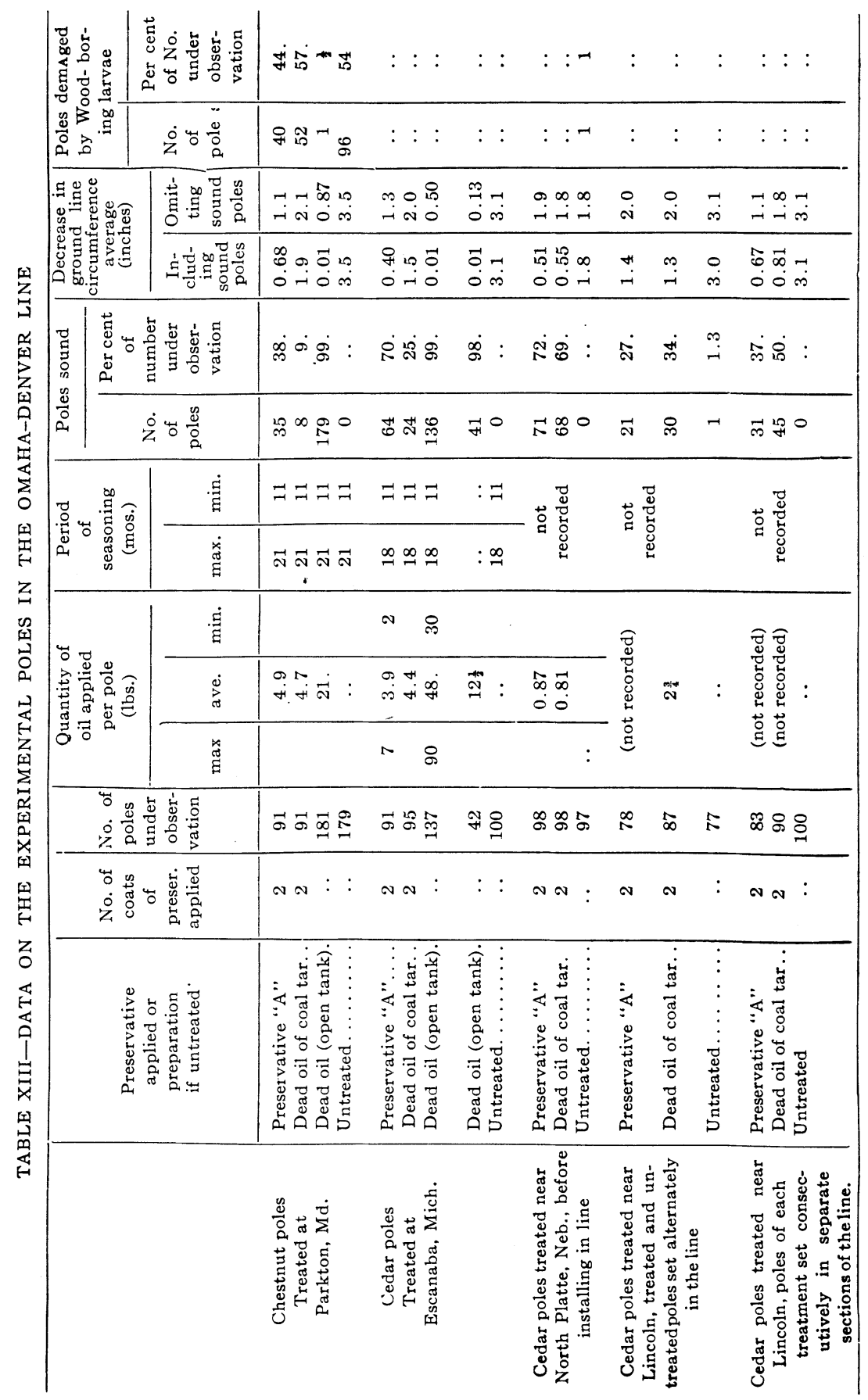


very likely held beyond the time necessary for seasoning. As will be pointed out subsequently, holding for a period much longer than that needed to bring about seasoning is disadvantageous from the standpoint of obtaining the best results in the way of preservation.

Another feature of interest brought out in the inspection of this line is the large proportion of chestnut poles in which boring beetles (parandra brunnea) were found. It has not been possible to determine whether these insects entered the poles after their setting or whether they first entered some of the poles at a point of storage and distributed themselves along the line after setting.

It will be noticed that the rate of decay, as indicated by the change in circumference, is relatively rapid. The average circumference change for treated poles showing decay would indicate that on many of these poles decay began not long after their setting.

Discussion of Experience with Butt-Treated Poles. The choice of treated poles in preference to untreated poles for constructing a line must necessarily be based on some expectation of an advantage to be gained. Ordinarily the advantage looked for would be longer life for the treated poles as compared with the untreated. A close determination of the gain in life due to treatment can only be secured when it is possible to compare the complete life history of a series of treated poles with that of a series of untreated poles exposed under comparative conditions.

It will be seen that the experience which we have just described has not been long enough to give the complete life history of any of the experimental series. It has, however, been long enough to substantiate the expectation that butt treatments will increase the life of poles and to yield considerable information of value to any one contemplating the use of treated poles.

The open tank treated poles show a negligible amount of impairment up to the date of the latest inspections. The superiority of the results obtained with the open tank poles as compared with the brush treated poles placed in the same localities is evident. Since so little change in condition has occurred in the case of the open tank poles, it is, however, impossible to find a basis for formulating an opinion as to what may be expected from these poles as the experiment continues. While, therefore, there is no question but that the best results in the 
butt treatment experiments are to be credited to the open tank treated poles, the data obtained from the brush treated poles yield much more information relative to the limitations of that process, so that we shall find it necessary to confine further discussion to the brush treatment.

A glance at the tables of results obtained with brush treatments in the different experimental series will show that the application of the treatment to poles has retarded the beginning of decay for a considerable number of years. A question immediately occurs, however, as to whether the rate of decay for treated poles may not be greater than for untreated poles so that the advantage due to this retardation of its incidence could ultimately be lost.

Some answer to this question is afforded by the data which we have been able to gather. In the case of one experimental

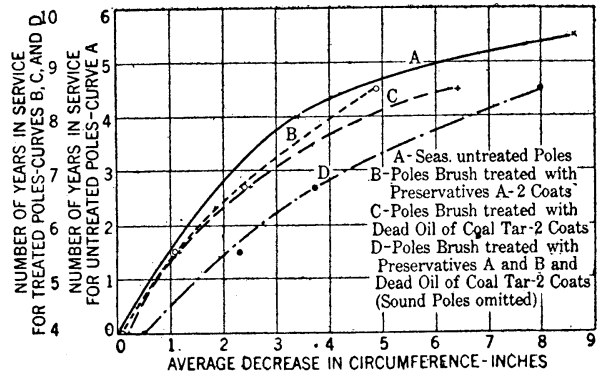

Fig. 1-Rate of Decay, Juniper Poles-Savannah-Meldrim Line

group, the juniper poles placed in the Savannah-Meldrim line, all but a few of the untreated specimens had, at the date of the last inspection, in 1913, reached the end of their serviceable life. By far the greater part of the treated specimens were still in serviceable condition at the 1913 inspection, so that in this one case we have direct evidence that an increased life will result from the treatment.

While substantial percentages of treated poles in all of the other experimental groups are still sound, decay on the corresponding untreated poles has not advanced so far as to have brought a majority of them to the end of their serviceable life. The data accumulated with respect to changes in the circumference of sound wood afford, however, an indication of what may be expected in the future from these experimental groups. To illustrate the application of the circumference data, Fig. 1 
and Fig. 2 are submitted. In Fig. 1 the average decrease in circumference is plotted against years of exposure for seasoned untreated juniper poles and for juniper poles brush treated with preservative A and with dead oil of coal tar. As a divisor which includes sound poles and poles which are decaying is necessarily used in obtaining the average decrease in circumference for the brush treated poles, we show also a curve for the average decrease in circumference of poles on which decay has started, combining in this case the results obtained with preservatives $\mathrm{A}$ and $\mathrm{B}$, and dead oil of coal tar, in order to include enough poles to insure representative results. In order to bring the curves for untreated and treated poles close together the scale for years of exposure of the treated poles has

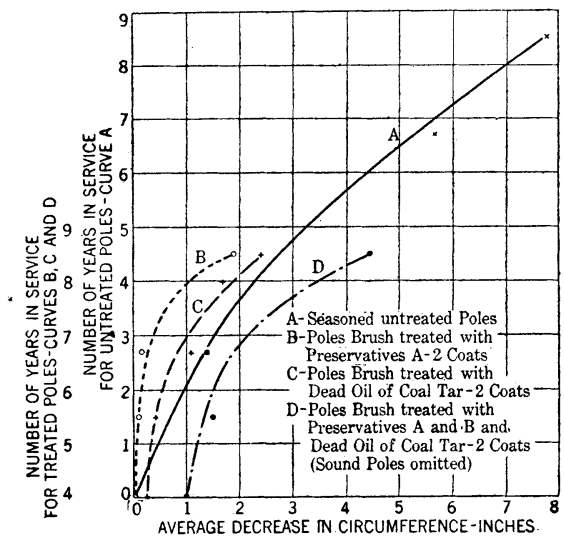

Fig. 2-Rate of Decay, Chestnut Poles-Savannah-Meldrim line

been shifted. Fig. 2 gives similar curves for the chestnut poles in the Savannah-Meldrim line. It will be seen on comparison of these curves that up to date no indication has been given that decay will proceed more rapidly on treated poles, once it starts, than it does upon untreated poles. The indications are, therefore, that any gains due to the retardation of the beginning of decay through treatment, will be retained.

Before concluding with this branch of the subject it seems worth while to describe an excellent illustration of the practical value of treated poles. The Savannah-Meldrim line was exposed to a severe wind storm in August 1911, which caused the breaking of twelve consecutively placed poles in the juniper section of the experimental series. Six of the twelve poles 
were untreated. Four more had been treated with coal tar and, as already noted, poles receiving this treatment have decayed very much as if they had received no treatment at all. All of these ten poles and one other pole which had been treated with preservative $\mathrm{E}$ had decayed to an extent requiring reconstruction, but the work of reconstruction had not at the time been performed. The twelfth pole which had received a brush treatment with dead oil of coal tar, was only slightly above the replacement dimensions for the line and was separated from the next treated pole, to which dead oil of coal tar had also been applied, by one of the untreated poles which fell. This lastmentioned pole treated with dead oil of coal tar was still sound and although unguyed and fully exposed to the force of the wind, stopped the break in its direction. In the other direction another brush treated pole which had suffered only slightly from decay also stopped the break, although it again was unguyed and exposed to the full force of the wind.

Increase in Life. In the present state of our information only approximate estimates can be given of the effect of brush treatment in increasing the life of poles. When all of a given group of poles have completed their period of service the computation of their average life is simple. The same method of computation can be applied when the number of poles in a group still left in service represents only a small percentage of the poles originally exposed as fairly large errors can be made in estimating the expectation of life for the poles still in service without causing any substantial deviation in the average life for the group.

The only groups of poles in the several experimental series which have deteriorated to a point where this method of computation can safely be applied are the untreated seasoned and "green" juniper poles in the Savannah-Meldrim line. The results of such a computation for these two groups of poles are shown in Table XIV, which indicates an average life of seven and two-tenths years for the seasoned untreated juniper poles placed in this line and an average life of seven and five-tenths years for the "green" untreated poles placed in this line. The conditions to which poles placed in this line are exposed were known to be unusually severe when the experiment was started and the location was chosen because of this. In spite of the very severe conditions of exposure none of the other experimental groups in this line have deteriorated to a point where 
we can find a basis for applying the same method of computation to determine their life.

One other method for estimating the gain in life due to treatment remains. It is based on the evidence illustrated in Fig. 1 and Fig. 2, indicating that when decay starts in a treated pole it does not proceed at any higher rate than in an untreated pole. If the rate of decay for treated poles is not greater than it is for untreated poles the number of years elapsing before the treated poles begin to decay will yield an approximate indication of the gain in life; as, under average conditions, not many months should elapse after setting before untreated poles show at least some slight signs of decay. Computations of

TABLE XIV

LIFE OF EXPERIMENTAL UNTREATED JUNIPER POLES IN THE SAVANNAH. MELDRIM LINE

\begin{tabular}{|c|c|c|c|c|c|}
\hline \multirow{2}{*}{$\begin{array}{c}\text { Year } \\
\text { of } \\
\text { inspection }\end{array}$} & \multirow{2}{*}{$\begin{array}{l}\text { Years } \\
\text { of } \\
\text { service }\end{array}$} & \multicolumn{2}{|c|}{ Green } & \multicolumn{2}{|c|}{ Seasoned } \\
\hline & & $\begin{array}{l}\text { No. of } \\
\text { poles } \\
\text { replaced }\end{array}$ & $\begin{array}{l}\text { Total pole } \\
\text { years in } \\
\text { service }\end{array}$ & $\begin{array}{l}\text { No. of } \\
\text { poles } \\
\text { replaced }\end{array}$ & $\begin{array}{c}\text { Total pole } \\
\text { years in } \\
\text { service }\end{array}$ \\
\hline 1909 & 4 & 0 & - & 1 & 4 \\
\hline 1910 & 5.5 & 28 & 154 & 38 & 209 \\
\hline 1912 & 7 & 23 & 161 & 28 & 196 \\
\hline 1913 & 8.5 & 24 & 204 & 22 & 187 \\
\hline *1915 & 10.5 & 17 & 178 & 13 & 136.5 \\
\hline & & - & $\ldots$ & - & \\
\hline & & $\begin{array}{c}92 \\
\text { Average life }\end{array}$ & $\begin{array}{c}697 \\
7.5 \text { years }\end{array}$ & 102 & $\begin{array}{l}732.5 \\
7.2 \text { years }\end{array}$ \\
\hline
\end{tabular}

*Es timated.

the average years to the beginning of decay for several of the experimental groups are shown in Table XV. It will be seen from the table that in the case of some of the experimental groups so many poles were still sound when last inspected as to make the estimate of the time at which decay would begin exercise considerable influence upon the results of the computation. The figures may also be from six months to a year above the actual range of life which will be shown by the brush treated poles due to the lag in the starting of decay upon untreated poles which has already been referred to. While these figures are only approximate it will be noticed that they indicate a greater addition to the life of poles through treatment for a northern location as compared with a southern location. 
Method of Failure of Brush Treatments. In making inspections of the treated poles special attention was given to determining the cause of the beginning of decay. In some cases decay had extended at the time of inspection to a point which made it impossible to reach a conclusion as to how it began. With only two or three exceptions, however, it has been found that the thin treated layer on the outside of the pole remained

TABLE XV

AVERAGE YEARS TO INITIATION OF DECAY FOR BRUSH-TREATED EXPERIMENTAL POLES (OMITTING PRESERVATIVE “ $F$ ")

(Computed for 100 poles on basis of percentages of sound poles)

SavanNah-MELdRIM Line

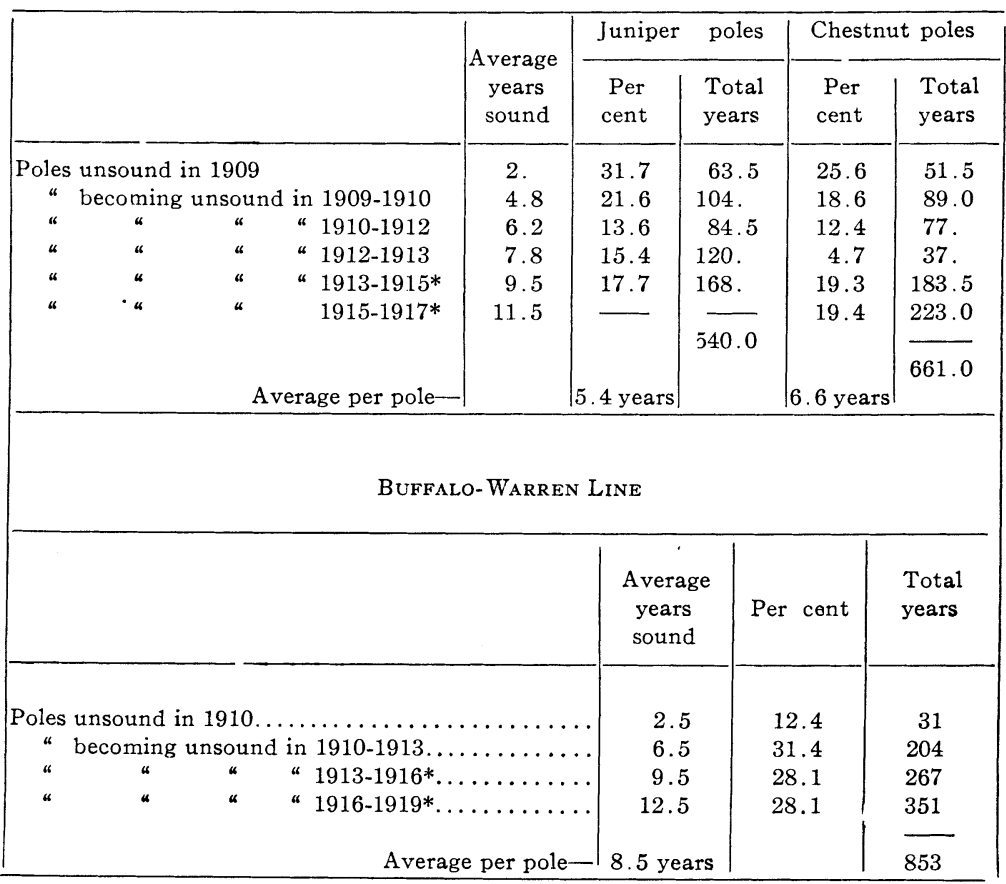

*Estimated.

sound after decay began. Any parts of the treated layer which covered decay were usually removed in the course of the inspection and the sound condition of the treated wood was readily checked by direct examination. Where a determination as to the point at which decay began was possible it was generally found that the presence of a check, split or other opening in the treated layer afforded a path through which 
the decay-producing organisms could gain access to the underlying untreated timber. From this point of entrance decay would spread usually affecting a thin layer just underneath the treated wood for some distance on either side of the point of entrance.

Fig. 3, which is an illustration of a brush-treated pole in the Buffalo-Warren line, shows excellently the usual conditions attending the starting of decay in brush-treated poles. This pole was sound when inspected in 1910 but on inspection in 1913 decay was found extending over the light-colored section shown at the bottom of the illustration. This section measured about six inches in width and the total depth of the cut was about one-quarter of an inch below the original external surface of the pole. The treated layer on the surface was sound but showed on inspection that there was soft wood beneath. On cutting the treated layer the thin underlying layer of decayed wood was found and removed before the photograph was taken. It will be noticed that there is a check visible in the illustration which passes through the center of the decayed section. This probably afforded the means for decay producing organisms to enter the pole and it will be noted that the decay had progressed about equal distances in either direction around the pole from this check.

The only other type of failure in brush-treated poles which has yet been noted was found in two or three specimens during the 1913 inspection of the Buffalo-Warren line. In the case of these few poles the external treated layer had turned soft and punky and could be easily scraped from the pole. The soft wood was collected from these poles and subjected to analysis. The same methods of extraction were used as had previously been applied to creosoted pine poles. It was found that about 5 per cent by weight of oily matter could be extracted from the sample. This oily matter on analysis was found to be practically free from substances distilling below 270 deg. cent. About half of the extract distilled between $270 \mathrm{deg}$. cent. and $360 \mathrm{deg}$. cent., at which point the distillation was stopped. The residue was found to be a viscous pitch. The extract was observed to be somewhat contaminated with substances derived from the wood. No definite conclusions can be drawn from this single experience but the evidence gathered suggests that in this case most of the preservative had been removed from the timber before decay started. Decay 
PLATE CLI,

A I. E. E.

VOL. $X X X I V, 1915$

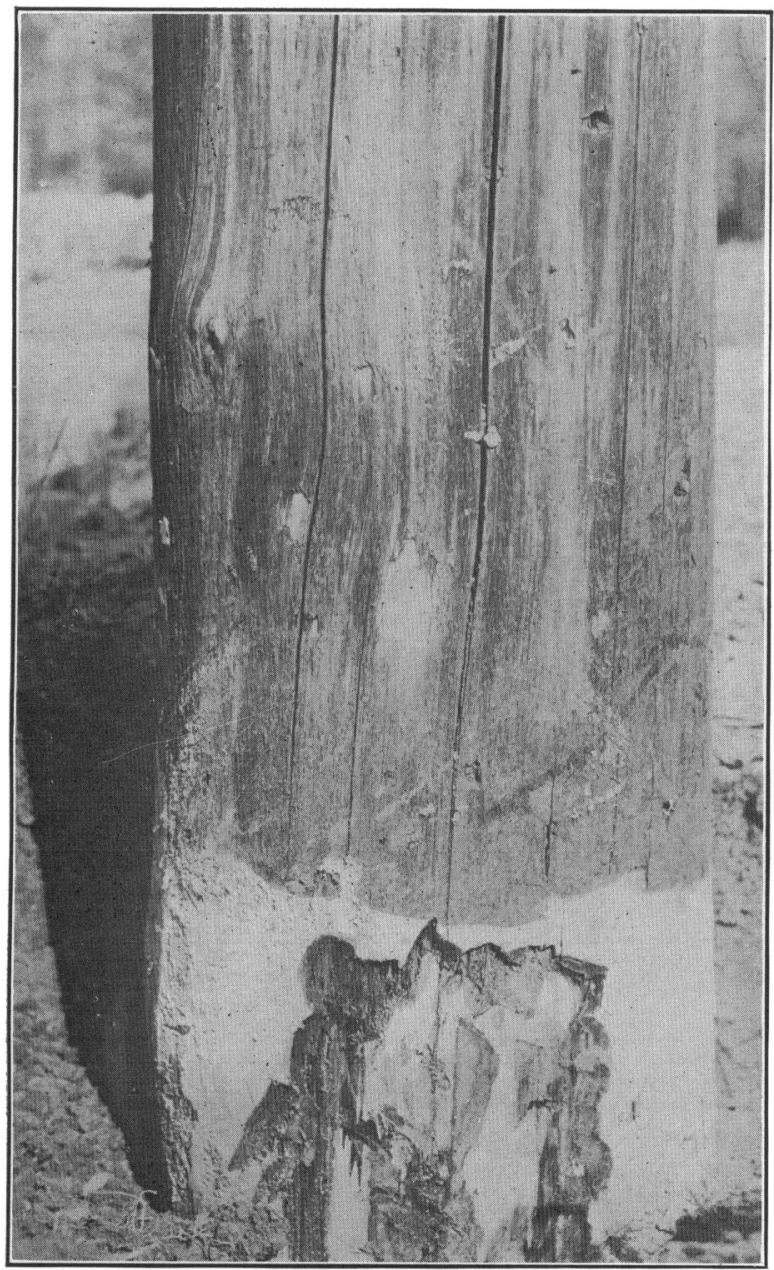

[RHODES AND HOSFORD]

Fig. 3-From Photograph of Brush-Treated Pole, Illustrating the Beginning of Decay 
of this type, however, cannot, on the basis of the data thus far gathered, be regarded as a common cause of the failure of brush treated poles.

Methods of Treatment. The application of preservative to the brush treated poles was generally made under similar conditions, as the principal object of the work was to determine the efficiency of a method which had already passed through a considerable development. It will be noticed on examining the tables, however, that several of the series of poles treated with particular preservatives were divided between one- and two-coat treatments; and that in the case of one preservative, dead oil of coal tar, three-coat treatments were also experimented with.

The effect of a one-coat treatment is most clearly shown in Table XII covering the Buffalo-Warren line. In this table there are several cases where approximately equal numbers of poles were given one-coat and two-coat treatments with the same preservative. In each case the superior results obtained with the two-coat treatment are obvious. In the SavannahMeldrim line only a few poles were given one-coat treatments and this was done only because the stock of preservative ran short. Because of the small number of poles receiving the one-coat treatment, the effect of peculiar characteristics in an individual pole is much enhanced so that no definite conclusions can be based upon the results obtained in this line.

The results of the experiments with three-coat treatments will be found in Table X, covering the Savannah-Meldrim line. No clear evidence of any advantage derived from applying the third coat is indicated.

With one exception, all of the preservatives were heated before application. Preservative C (see Table X, SavannahMeldrim line) was applied cold to all except a few of the poles treated with it. The results obtained with the poles treated with cold preservative are only slightly inferior to the results obtained with the poles to which the hot preservative was applied. A somewhat greater amount of the preservative was absorbed when it was heated before application.

Comparison of Preservatives Used. It will be noticed that none of the seven preservatives experimented with shows consistently superior results to the others. Some of the preservatives have given irregular results, showing up well with one group in an experimental series and poorly in another. Preservative A and 
dead oil of coal tar give the most consistent results in the Savannah-Meldrim and the Buffalo-Warren experiments, where a number of other preservatives were employed. In the case of the Omaha-Denver line, where the other preservatives were not included in the experiment, the relation between the results obtained with these two preservatives is about what was to be expected from them in view of their previous record in the other lines. Except as a preservative contained a large proportion of constituents soluble in water, it would be expected to remain in the ground line section of poles for a number of years as the experience with creosoted pine poles indicates that preservative is lost by evaporation much more slowly from this part of the pole than from the upper sections. As the characteristic type of failure for brush-treated poles has been due to mechanical causes such as the opening of checks or the cutting of the treated layer, it would be expected that the differences between the results obtained with the different preservatives experimented with would not be great, and the summarized data accord fairly well with this expectation.

The Effect of Seasoning. At the time these experiments were started it was generally assumed that seasoning would produce a substantial increase in the life of poles. One thing aimed at in the experiments was to secure a direct demonstration of this generalization. It will be noticed, however, that in the case of the Savannah-Meldrim line appreciably better results are shown by the "green " poles and that in the case of the BuffaloWarren line the seasoned poles show only a slight advantage over the "green" poles.

In considering these results it must be borne in mind that the conditions of the experiment made it necessary to collect poles each month over a period of about a year and to hold the poles first collected until it was certain that the poles last collected had been thoroughly seasoned. While the poles were skidded and other precautions were taken to keep them in good condition and free from decay, it will be seen that a part of the seasoned poles were held for a period considerably in excess of that normally required for seasoning.

In the Savannah-Meldrim line, poles which received the same amount of seasoning were installed in the same sub-group and consequently in the same section of the line. In Fig. 4 we have plotted the average decrease in circumference for each month's group of seasoned juniper poles, and for comparison 
with it we have plotted the decrease in circumference for the "green" poles included in the same sub-group with each lot of seasoned poles, and therefore exposed to approximately the same conditions. The data are plotted only for the inspections of 1909 and 1910 as the removals subsequent to 1910 preclude the showing of comparative data. Fig. 5 is a corresponding plot for the chestnut poles in the Savannah-Meldrim line.

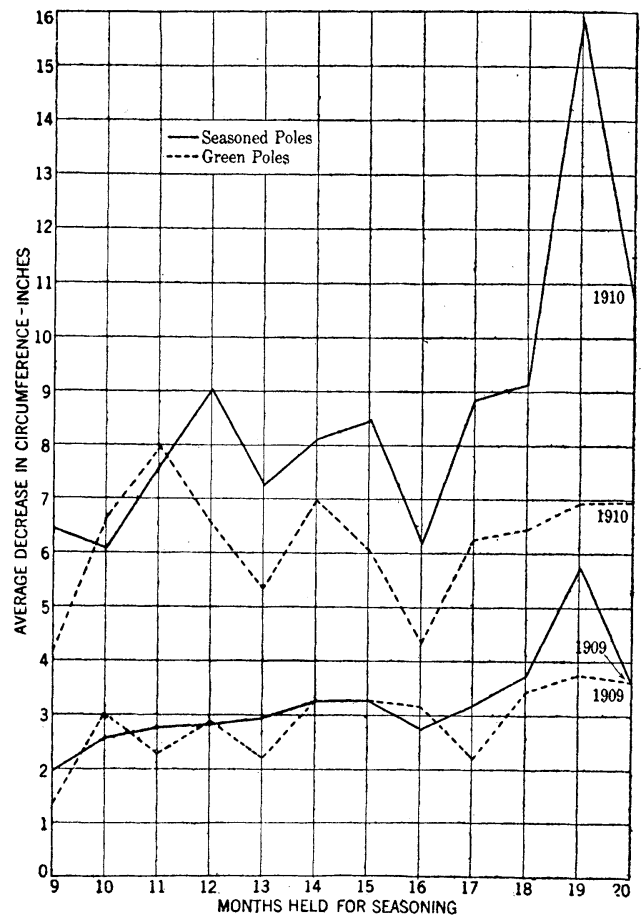

Fig. 4-Comparison of Rate of Decay-Seasoned and Green Juniper Poles

Seasoned poles plotted by sub-groups according to duration of seasoning. Green poles plotted against seasoned poles in same sub-group.

Fig. 4 shows a strong tendency to an increasing rate of decay for the longer periods of seasoning. In Fig. 5 this tendency is not so marked, although there is a slight trend towards a higher rate of decay as the period of seasoning increases.

It was also found that the treated poles in this line which had begun to decay showed distinctly higher rates of decay in the case of poles subjected to the longer periods of seasoning. The indications are, therefore, that the superiority of "green" 
poles over seasoned poles in the Savannah-Meldrim experiment is, in part at least, due to the excessive duration of the period of seasoning. The conclusion to be drawn from this experience seems to be that seasoning affords at best only a slight increase in the life of poles and that the greatest advantage to be derived from seasoning is that the pole is brought into a condition suitable for receiving a butt treatment.

Insect Damage to Poles. For many years insects have been found in decaying poles but it is only recently that systematic study of insect damage to poles has been attempted. The

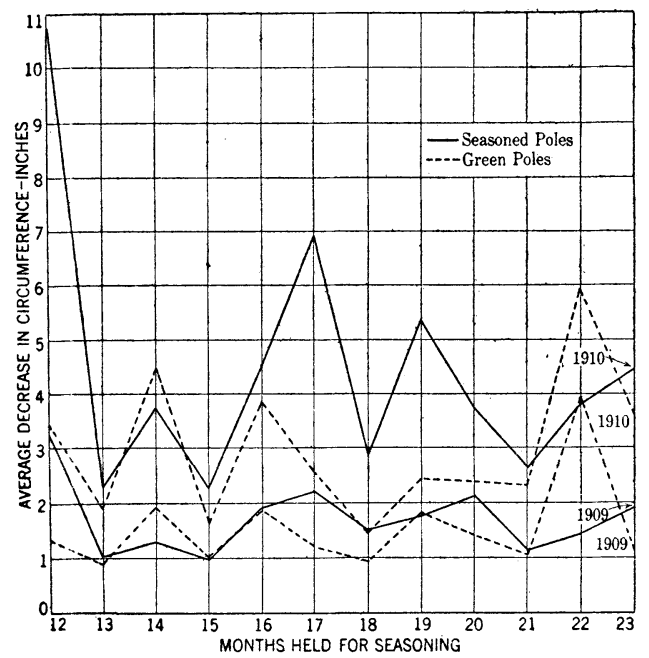

Fig. 5-Comparison of Rates of Decay-Seasoned and Green Untreated Chestnut Poles

Seasoned poles plotted by sub-groups according to duration of seasoning. Green poles plotted against seasoned poles in same sub-group.

study of this problem was proposed in 1910 by Dr. A. D. Hopkins of the Bureau of Entomology, whose assistant, Mr. T. E. Snyder, had just completed the investigation of a case where a wood-boring beetle (parandra brunnea) had been found causing serious injury to a pole line. The inspection of the experiments with butt treated poles was, at that time, just becoming active. Through the participation of Mr. Snyder in one of the early inspections, a foundation was laid for future work through the training of the inspection force in methods for gathering data bearing on insect damage. Through following these methods, and with the assistance afforded by the Bureau 
of Entomology in identifying specimens collected by inspectors, a valuable record of insect damage as affecting the experimental poles has been gathered.

Substantial insect damage has come from two very different sources. Termites, or white ants as they are often referred to colloquially, have long been recognized as a source of injury to timber, particularly in the South, where the warm climate is favorable to their prevalence. The damage caused by the wood-boring larvae of beetles has only recently received recognition. Both of these classes of insect are fairly common causes of damage to pole timber, and data as to the effect upon their incidence of methods of preparing and treating poles are therefore worthy of attention.

TABLE XVI.

BUFFALO-WARREN LINE, DAMAGE TO POLES BY WOOD-BORING INSECTS

\begin{tabular}{|c|c|c|c|c|c|c|}
\hline $\begin{array}{l}\text { Method of } \\
\text { preparation } \\
\text { applied to } \\
\text { poles }\end{array}$ & $\begin{array}{c}\text { Num- } \\
\text { ber } \\
\text { poles } \\
\text { ex- } \\
\text { posed }\end{array}$ & $\begin{array}{l}\text { No. } \\
\text { poles } \\
\text { show- } \\
\text { ing } \\
\text { decay } \\
\text { to } 1910\end{array}$ & $\begin{array}{c}\text { No. } \\
\text { poles } \\
\text { dam- } \\
\text { aged } \\
\text { by wood } \\
\text { borers } \\
\text { to } 1910\end{array}$ & $\begin{array}{c}\text { No. } \\
\text { poles } \\
\text { show- } \\
\text { ing } \\
\text { decay } \\
\text { to } 1913\end{array}$ & $\begin{array}{c}\text { No. } \\
\text { poles } \\
\text { dam- } \\
\text { aged } \\
\text { by wood } \\
\text { borers } \\
\text { to } 1913\end{array}$ & $\begin{array}{l}\text { No. poles } \\
\text { damaged } \\
\text { by wood } \\
\text { borers } \\
\text { in } 1910 . \\
\text { showing no } \\
\text { new damage } \\
\text { in } 1913\end{array}$ \\
\hline Green Untreated & 200 & 200 & 8 & 200 & 16 & 4 \\
\hline Seasoned “ & 350 & 349 & 2 & 350 & 11 & 1 \\
\hline $\begin{array}{l}\text { Coated with Tar } \\
\text { Brush Treated- }\end{array}$ & 48 & 47 & 1 & 48 & 2 & - \\
\hline Brush Treated- Preservative "F" & 79 & 59 & 2 & 78 & 3 & 2 \\
\hline $\begin{array}{l}\text { Brush Treated- } \\
\text { Preservative "A " } \\
\text { Brush Treated- }\end{array}$ & 74 & 10 & - & 31 & 1 & - \\
\hline Preservative " $\mathrm{B}$ " & 76 & 11 & - & 42 & 1 & - \\
\hline
\end{tabular}

The results of studies of wood-boring larvae (particularly parandra brunnea) have been published by Mr. Snyder.* Reference is made to his publications for details concerning their attack on poles. For our purposes it is sufficient to note that once entrance to a pole is obtained, the larvae bore deeply into the heart-wood and consequently where their number is large a complete honey combing of the pole cross-section soon results. Wood borers have been found both in the OmahaDenver line and the Buffalo-Warren line. Data relative to their attack in the first named line are included in Table XIII. Data from the Buffalo-Warren line are summarized in Table XVI.

*See Appendix A-Bibliography. 
It will be noticed that in the Buffalo-Warren line the damage from wood-boring larvae has been almost wholly confined to the two untreated groups of poles. The two treated poles yielding evidence of damage in 1910 were members of the group showing the highest proportion of unsound poles. Of the three treated poles first showing signs of damage in 1913, two had been noted as unsound in the previous inspection. Larvae were found in eight poles in 1910. Two of the eight poles in which larvae were found in 1910 were free from signs of wood-boring larvae in 1913. In these two poles, the presence of only one or two larvae was reported in 1910. It seems probable that the cleaning applied to the poles in connection with the inspection caused the removal of the few larvae then present.

The data given in Table XIII for the Omaha-Denver line represent the results of the first inspection for condition. Large percentages of both treated and untreated poles were found to be attacked by wood-boring larvae. The percentage of brushtreated poles attacked to the total brush-treated poles installed is a little lower than the percentage of untreated poles attacked to untreated poles installed. The percentage of poles attacked to poles showing decay is, however, higher for the brush-treated poles than for the untreated poles.

Experience with wood-boring larvae has not yet been extensive enough to establish definite conclusions as to methods of inhibiting their attack. The indications are, however, that the beetles will not deposit eggs on poles unless they can find a soft or decayed spot, so that as long as a treatment remains effective it should be counted upon to prevent damage from wood-boring insects.

The principal insect damage found upon the poles placed in the Savannah-Meldrim line was due to termites. A few cases of attack by termites were also noticed when the Omaha-Denver line was examined. Termites do not like direct sunlight and in attacking poles consequently begin to cut their galleries a little below the outer surface of the timber. A few cases have been noticed where outside galleries of cemented sand have been built across sections of the pole surface where for some reason the wood was not attacked. In a number of cases where a pole was badly infested by termites, small numbers and a slight attack were noticed at adjacent poles, suggesting that the large colony gathered about the heavily attacked pole may have extended its sphere of influence to neighboring poles. 
No cases were noticed of termite attack upon the thin outside layer of brush-treated poles in which the preservative is located. The tendency of the insect to avoid the light, however, would result in leaving untouched a surface layer of wood of approximately the thickness of the treated layer. In a number of cases termites were found in small decayed spots where the initial failure of a brush-treated pole had taken place. The relation of these spots to small checks and other openings in the treated layer has already been discussed. No direct evidence was obtainable as to whether the decay-producing organism or the termites first entered such poles.

The summarized results of the first two inspections of the Savannah-Meldrim line show that 38 per cent of the unsound treated poles bore evidence of the attack of termites, while 37 per cent of the untreated poles gave evidence of such attack. Owing to the substantial reconstruction of untreated poles which followed the 1910 inspection this statistical comparison cannot be continued for the following years. The equality in the percentages of decayed untreated poles and decayed treated poles which were infested by termites suggests, however, that termites follow the decay. In support of this conclusion it is also to be noted that there were a number of cases. where sound brush-treated poles were located between two untreated poles, both of which were badly infested by termites. The indications are, therefore, that treatment retards the attack of termites, and that the retardation is probably due to delaying the beginning of decay.

Some instances, however, of termites attacking treated wood were noticed in the inspection of the whole length treated pine poles in the Montgomery-New Orleans line. This attack came after the poles had been exposed to the action of the weather for many years and suggests that ultimately changes may occur in treated wood which permit termites to work upon it. With brush treatments, however, which give only light penetrations, the available information indicates that in the average case deterioration will set in much earlier than it does with the heavier treatments. The evidence just cited indicates that brush treatments may have a direct effect in preventing the attack of termites. The heavier treatments would, of course, produce the same effect as the brush treatment, but may lose their power of inhibiting termite attack before the power to inhibit decay is gone. 


\section{Conclusion}

Because of the present incomplete stage of our experience with the different types of treatment described, conclusions can be reached for only a part of the problems whose solution was sought. The seasoning of poles offers at best only moderate advantages in the way of increased life. Its greatest value is as a preparation for the successful application of preservatives. The practise of applying to poles preservatives high in antiseptic power and insoluble in water has been shown to yield increased life. The amount of preservative applied and the depth to which it is made to penetrate appear to exercise controlling influences upon the results obtained. Mechanical failure of the treated layer is indicated as the principal limit to the effectiveness of light applications of preservatives.

In closing we wish to acknowledge our indebtedness to $\mathrm{Mr}$. E. B. Griffen, for his assistance in carrying out the work of inspection and analyzing the data obtained; and to Mr. C. C. Fritz and Mr. H. D. Cutler, who have also assisted in obtaining the data on which our contribution is based. For careful attention to the analyses and other chemical work connected with the studies of treated poles we are indebted to Mr. G. O. Bassett and Mr. H. G. Walker. We also gratefully acknowledge our indebtedness to many past and present members of the Forest Service and to the representatives of the Bureau of Entomology who have taken part in the experiments with treated poles.

\section{APPENDIX A}

Bibliography of Publications Relating to Experimental Poles Prolonging the Life of Telephone Poles, by Henry Grinnell, Year Book of Department of Agriculture for 1905.

The Open Tank Method for the Treatment of Timber, by Carl G. Crawford, Forest Service Ciruclar No. 101, July 2, 1907.

Seasoning of Telephone and Telegraph Poles, by Henry Grinnell, Forest Service Circular No. 103, July 6, 1907.

Brush and Tank Pole Treatments, by Carl G. Crawford, Forest Service Circular No. 104, July 11, 1907.

Changes Which Take Place in Coal Tar Creosote During Exposure, by Hermann Von Schrenk, E. B. Fulks, A. L. Kammerer, Bulletin No. 93, American Railway Engineering and Maintenance of Way Association, November, 1907.

The Seasoning and Preservative Treatment of Arborvitae Poles, by C. Stowell Smith, Forest Service Circular No. 136, January 18, 1908.

Progress in Chestnut Pole Preservation, by Howard F. Weiss, Forest Service Circular No. 147, April 27, 1908. 
Report on Creosoted Yellow Pine Poles in the Norfolk-Washington Line and in the Montgomery-New Orleans Line, Appendix B to Report of Committee on Preservative Treatment of Poles and Crossarms, National Electric Light Association, May, 1910.

Damage to Chestnut Telephone and Telegraph Poles by Wood Boring Insects, by Thomas E. Snyder, Bureau of Entomology Bulletin No. 94, Part, 1, Dec. 31, 1910.

Damage to Telephone and Telegraph Poles by Wood Boring Insects. by T. E. Snyder, Bureau of Entomology Circular No. 134, March 7, 1911.

Preservative Treatment of Poles, by William H. Kempfer, Forest Service Bulletin No. 84, June 12, 1911.

Condition of Experimental Chestnut Poles, by Carlile P. Winslow, Forest Service Circular No. 198, September 26, 1912.

The Air Seasoning of Timber, by William H. Kempfer, Bulletin No, 161, American Railway Engineering Association, November, 1913.

Condition of Experimental Poles, by C. H. Teesdale, Engineering News, November 27, 1913.

Service Tests of Treated and Untreated Telephone Poles, by C. H. Teesdale, Telephony, April 3, 1915.

\section{APPENDIX B}

\section{Analyses of Preservatives}

\section{WhOLE LENGTH TREATMENTS}

Numerous analyses of dead oil of coal tar supplied for the whole length treatments were made in the case of both groups of poles under observation. As it is not possible to indicate any relation between the dead oil of coal tar covered by a specific analyses and any particular pole installed, only averages of all of the analyses made are given.

Washington-Norfolk line. Twenty-eight analyses were made of the dead oil supplied for treating poles used in this line. The average of the results of these analyses is as follows:

\section{Distillates}

Loss-water, etc., to 170 deg. cent.......... 1 per cent

170 deg. cent. to 205 " "

205 " " to 210 " $" \ldots \ldots \ldots \ldots \ldots \ldots 4$ " "

210 " " to 235 " $" \ldots \ldots \ldots \ldots \ldots .45$ " "

235 " " to 240 " " $\ldots \ldots \ldots \ldots \ldots, 7$ "

240 " " to 270 " " $\ldots \ldots \ldots \ldots \ldots 16$ " "

270 " " to 316 " " $\ldots \ldots \ldots \ldots \ldots . \ldots . \ldots . \ldots$

Residue above 316 deg. cent............16 " "

Naphthalene

205 deg. cent. to 235 " " $\ldots \ldots \ldots \ldots \ldots 49$ " "

Oil not distilling below

270 " $" \ldots \ldots \ldots \ldots \ldots 25$ "

Specific gravity...... . . . . . . . . . . . . . . . 1.022

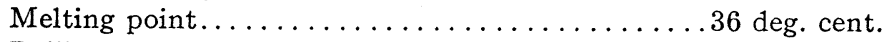

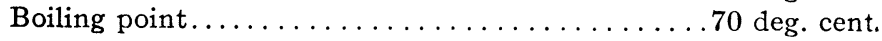


Montgomery-New Orleans line. Thirty-eight analyses were made of the dead oil supplied for treating poles used in this line. The average of the results of these analyses is as follows:

\section{Distillates}

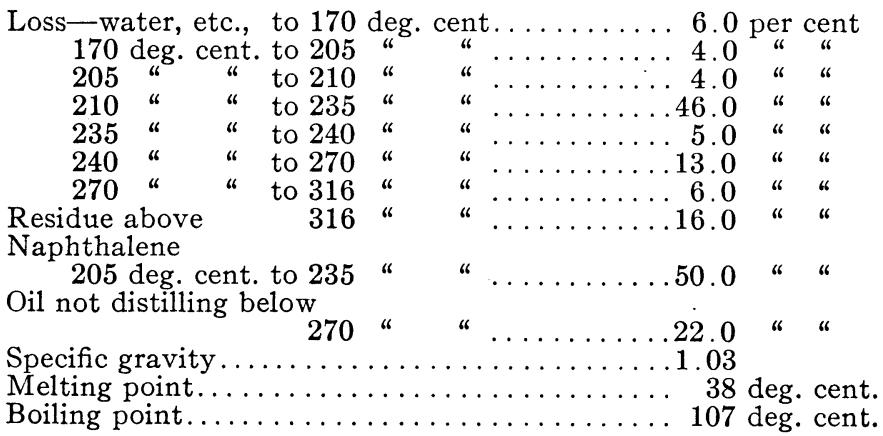

\section{Butt Treatments}

Most of the detailed analyses of the preservatives used for brush treatment were made on samples representing material applied to poles placed in the Savannah-Meldrim line. There is no reason for believing, however, that the composition of the preservatives supplied for the Buffalo-Warren line differed appreciably from that of the analyzed samples.

Savannah-Meldrim line.

Preservative A.

Series I

Specific gravity at $17 \mathrm{deg}$. cent........1.121

Series II.

Flashing point...................

Burning point..............164 deg. cent.

Distillates:

Loss.................. 0.19 per cent

Below 235 deg. cent. . . . . . . . . . 0.41

From 235 deg. cent. to $315 \mathrm{deg}$. cent 29.16

Residue above 315 deg. cent........ 70.24

66

Solids, 1.7 deg. to 4.4 deg. cent. . . . . . No separation

Tar acids................. 1.12 per cent

Mineral matter.

0.16 "

1.122

137 deg. cent. 168 deg. cent

0.22 per cent

0.61 " "

26.97 " "

72.20 " "

No separation

1.16 per cent

0.05

\section{Preservative $B$}

Series I. Specific gravity at $17 \mathrm{deg}$. cent.........1.134

Flashing point................ 135 deg. cent. Burning point............... Distillates:

Loss..................... 0.13 per cent

Below 235 deg. cent............. 0.35

From 235 deg. cent. to 315 deg. cent. 28.84

Residue over 315 deg. cent........70.68

" 6

Solids, 1.7 deg. cent. to 4.4 deg. cent. ... No separation Tar acids................. 1.30 per cent

Mineral matter............... 0.31

Series II.

1.134

$135 \mathrm{deg}$. cent

162 deg. cent

0.19 per cent

0.31 " "

30.10 " "

69.40 “ “

No separation

1.30 per cent

0.47 " 
Preservative C

Series I.

Series II.

Specific gravity at $17 \mathrm{deg}$. cent........1.032

1.031

Flashing point.............. 90 deg. cent.

90 deg. cent

Burning point............. 99 deg. cent.

\section{Distillates:}

101 deg. cent

Loss.................... 0.65 per cent

Below 235 deg. cent.............15.14 " "

From 235 deg. cent. to 315 deg. cent. 26.23 " “

Residue above 315 deg. cent.......57.98 " "
Solids, $1.7 \mathrm{deg}$. cent. to $4.4 \mathrm{deg}$. cent. . . No separation

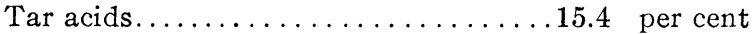

Mineral matter................. 0.14 " "

Preservative E

Series I.

0.53 per cent

14.97 " "

25.60 " "

58.90 " "

No separation

0.02 per cent

16.3

Series II.

Specific gravity at 17 deg. cent........1.035

1.035

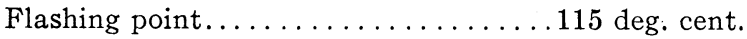

111 deg. cent

Burning point. . . . . . . . . . . 129 deg. cent.

Distillates:

123 deg. cent

Loss....................... 0.29 per cent

Below 235 deg. cent...........2.51 " "

From 235 deg. cent. to 315 deg. cent. 26.00 " "

Residue at 315 deg. cent..........71.20 " "

Solids, $1.7 \mathrm{deg}$. cent. to $4.4 \mathrm{deg}$. cent. . . No separation

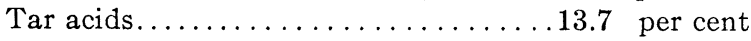
Mineral matter............... 0.04 " "

0.51 per cent
3.65 “
24.74 "
71.10 "

No separation 11.8 per cent None

\section{Preservative F}

$\begin{aligned} \text { Specific gravity at } 38 \mathrm{deg} \text {. cent........ Series I. } & \text { Series II. } \\ \text { Distillates: } & 1.005\end{aligned}$

Distillates:

Below 170 deg. cent...........26.66 per cent

From 170 deg. cent. to $205 \mathrm{deg}$. cent. 17.39

From 205 deg. cent. to 210 deg. cent. 9.27

From 210 deg. cent. to 235 deg. cent. 25.92

From 235 deg. cent. to 240

From 240 deg. cent. to 270

From 270 deg. cent. to 300

") 15.98 " "

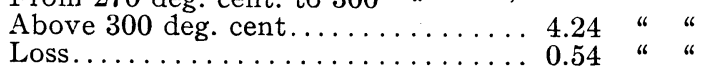

Total................. $\overline{100.00 \text { per cent }}$

Naphthalene....................35.19 " "

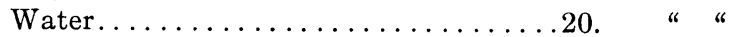

Tar acids.................. " "

Note..................................... other foreign matter present.

96.90 per cent

0.10 " "

0.00 " "

0.00 " "

0.15 " "

0.85 " "

2.00 " "

100.00 per cent

None

90. “ "

1 " “

Sticks, sand, and other foreign matter present. 
Dead Oil of Coal TaR

Specific gravity at $38 \mathrm{deg}$. cent......... $\begin{gathered}\text { Series } \mathrm{I} \\ \mathrm{I}\end{gathered}$.

Distillates:

Below 170 deg. cent........... 0.17 per cent

From 170 deg. cent. to 205 deg. cent. 1.25

From 205 deg. cent. to 210 deg. cent. 1.14

From $210 \mathrm{deg}$. cent. to $235 \mathrm{deg}$. cent. 43.96

From 235 deg. cent. to 240 deg. cent. 6.66

From 240 deg. cent. to 270 deg. cent. 19.48

From 270 deg. cent. to 300 deg. cent. 10.07

Residue above 300 deg. cent........17.00

Loss. . .

0.27

Series II.

1.035

Total.

100.00 per cent

Naphthalene........................

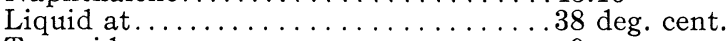

Tar acids................ $9 . \ldots$ per cent

Water.................... None

$\begin{array}{r}0.09 \text { per cent } \\ 0.70 \text { “ } \\ 0.74 \text { “ } \\ 45.92 \text { “ } \\ 6.12 \text { “ } \\ 20.03 \text { “ } \\ 9.61 \text { “ } \\ 16.30 \text { “ } \\ 0.49 \text { “ } \\ \hline\end{array}$

100.00 per cent 46.66

38 deg. cent.

8.3 per cent None

\section{Buffalo-Warren line.}

Dead Oil of Coal Tar used in Butt Treatment Tanks, ${ }^{7}$ Mt. Arlington, N.J. Sample represents oil in the tank during third run, June 17, 1905.

Specific gravity at 38 deg. cent............ 1.018

Condition at 38 deg. cent............. Liquid

\section{Fractionation}

Fraction No. 1 to 170 deg. cent............ 0.09 per cent

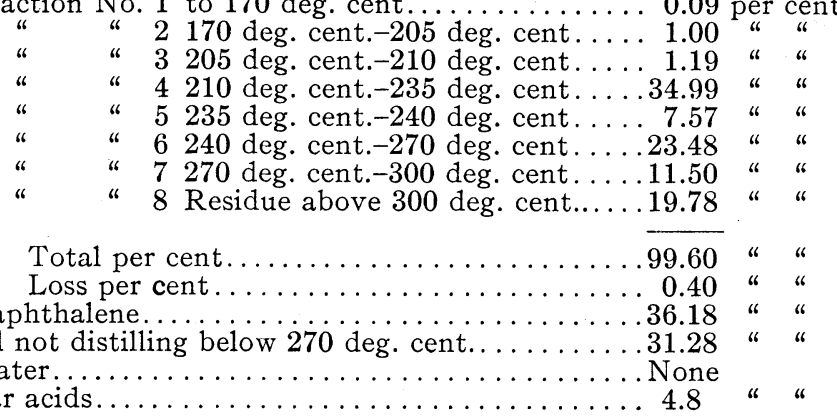

\section{Omaha-Denver line.}

Dead Oil of Coal Tar Used at Escanaba, Michigan. Condition of Oil at 38 deg. cent............. Solids Separate Liquid at $42 \mathrm{deg}$. cent. Specific Gravity at 42 deg. cent. . 1.028

\section{Fractionation}

1. to 170 deg. cent............ None

2. 170 deg. cent. to 205 deg. cent.............

3. 205 deg. cent. to 210 deg. cent................. 0.81 per cent

4. 210 deg. cent. to 235 deg. cent............ .56.80

5. $235 \mathrm{deg}$. cent. to $240 \mathrm{deg}$. cent............ . 5.88

6. $24 \Omega$ deg. cent. to 270 deg. cent............ 15.78

7. 270 deg. cent. to 300 deg. cent............. 7.32

Residue above 300 deg. cent. . . . . . . . . . . . 13.10

Total per cent.....................99.69

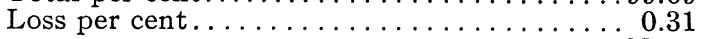

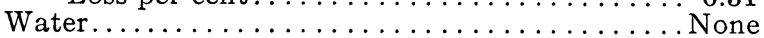

Naphthalene.................57.61 per cent

Tar acids...................... 
Dead Oil of Coal Tar Used for Brush Treatments in Nebraska

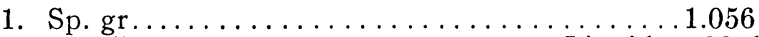

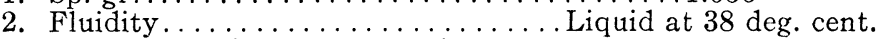

3. Distillation of $100-\mathrm{gm}$. sample
(a) $0-205$
None
(b) 205-235
11.39 per cent
(c) $0-31$
79.68
(d) Residue above 315
Soft and plastic
(e) Water
None
Tar acids.................. 3.00 per cent
Sulphonation residue
None
Flash point.................. 98 deg. cent.
Burning point.................

Preservative A (Used for Brush Treatments in Nebraska)

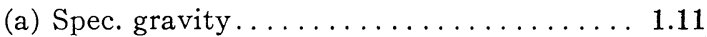

(b) Flashing point...............138 deg. cent.

(c) Burning point.................

Fractional Distillation:

Distillate up to $235 \mathrm{deg}$. cent. . . . . . . . 1.28 per cent " between $235 \mathrm{deg}$. and $300 \mathrm{deg}$. cent... 3.16 per cent

Residue above 300 deg. cent............ . . . . .

Fluidity...................... Fluid at 38 deg. cent. Tar acids.................. 0.1 per cent

Ash...

0.12 " 


\section{Discussion on "Recent Results Obtained from the Pre- servative Treatment of Telephone Poles" (Rhodes and Hosford), St. Louis, Mo., Остовer 19, 1915.}

Herman von Schrenk: Mr. Hosford brought out the important factor about the changes which take place in poles after service and I note throughout the discussion, in the report and in the tables that the word decay is used. I judge from the description which Mr. Hosford gave us just now that the word decay as he used it, refers not so much to the impregnated portions of the pole as to the parts which lie beneath those portions. The experience which we have had in other structures, notably in railroad trestles, with piling, etc., has been entirely in accord with the observations he gives here. I only recently had occasion to condemn a railroad structure of creosoted piling, 180 feet long, after only four years of service, which showed marked decay, when, as a matter of fact those parts of the wood impregnated with the creosoted oil were perfectly sound; but, just as in the case of the poles described as being subjected to brush treatment, the fungus spores had penetrated through the season checks and brought about decay underneath. What I want to know is, did Mr. Hosford in an examination of these poles find any of that decay in the impregnated sections of the wood-this question refers particularly to the butt or full cell process-in which the creosote had penetrated?

The second point I would like to call particular attention to is the conclusion I reached after reading this paper, emphasizing, first of all the high efficiency of the poles which were treated so they received the maximum impregnation, and in the second place, a maximum retention of the preservative. I was very much impressed at the last inspection I made of the German government telegraph and telephone lines, where the maximum amount of creosote was injected. The percentage of failures was very, very low, where that proceeding had been followed. The difference between the brush-treated poles and the so-called tank or full cell treated poles, as shown by these records, is vey striking; and I would like to have Mr. Hosford confirm the impression which I have obtained here, that judging by the results which they have secured so far, there is every indication that butt treated poles or full cell treated poles will give a very much higher probability of longer return on the investment than is the case with the brush-treated pole.

The third point I would like to bring out-and I may perhaps be treading on dangerous ground in raising this point-is to ask Mr. Hosford whether there was any particular reason for initialing by letters the results of the so-called proprietary preservatives, in other words the trade-marked compounds. I would personally like to know what " $A, B$ and $C$ " stand for. The great trouble with these proprietary compounds is that they 
come to us full of claims and with certificates from engineers all over the country, showing what beautiful results these substances give. Instead of charging ten or twelve cents a gallon for high-grade coal tar, they want seventy-five or eighty cents a gallon. I should think it too bad, unless there is some particular reason to the contrary, if these particular pieces of research could not be made available to all who are interested, with a clear statement of the preservatives and what they stand for. We are confronted at the present time with an agitation in Congress on this particular subject. I doubt not that many of you have received circulars calling for a "Pure Food Timber Preservative Law" to be enacted by Congress. I have received copies of these circulars from engineers in various parts of the United States, including even to-day's mail, asking what action they should take. One of these circulars was sent to me as chairman of a committee of the American Society for Testing Materials, asking that that organization should take some action. While that is a good thing for a proprietary compound, there are obvious reasons why coal tar should not be subject to that particular kind of restriction, and I ask Mr. Hosford if we could get him to divulge what these symbols stand for.

The fourth point in my mind is, in making the chemical examination of the poles, was any attention given to the difference between the oil on the outside of the pole, near the ground line, and that further towards the middle of the pole? That is a very vital point in the discussions now going on in connection with specifications for treated poles.

I was particularly impressed with the statement that the poles with heavier outside evidence of treatment, as indicated by the hardened tar, had a greater tendency to resist decay, reinforcing the conclusion that life will increase with the amount of preservative applied. I would like to know whether all indications so far do not point in favor of a generally increasing tendency both among operations on telephone lines and in the railway practise, to try to treat the timber irrespective of the amount of oil used, in other words, to treat the timber with the amount of preservative it will actually hold, instead of with a given quantity per cubic foot. Of course we run into objections from the financial department, because we would probably treat the poles with more oil than they would pay for. Do not all the results shown here indicate that the better the treatment the better the probabilities of length of life to be obtained?

Clyde H. Teesdale: Mr. Rhodes and Mr. Hosford have shown that brush-treated chestnut and cedar poles will probably last from 5 to 6 years longer than the untreated poles. The cost of this treatment is very low. With coal-tar creosote it ought not to be over 30 cents for a 30 -foot pole if a large number are treated at a time in one place. With an added life of 4 to 5 years, a cost as low as this offers a very good return. This is particularly true in the case of poles used by electric light and 
power companies, who usually use larger poles than a telephone company. Where large poles are used a greatly increased first cost makes it possible to pay a considerable price for a preservative treatment, provided a good increase in life is obtained. The question of giving a thorough open-tank treatment to large poles is, therefore, worthy of serious consideration.

In Mr. Hosford's paper the brush treatment is dealt with to the greatest extent, and is the one with which the most definite results were obtained. It appears desirable, therefore, to discuss the limitations of this method of treatment. It has been found, for example, that brush-treated western yellow pine poles last practically no longer than similar untreated ones. Furthermore, it is obvious that woods which do not last well above the ground line will not be benefited by either a brush or opentank treatment at the ground line. Therefore, such species as sap cypress and sap yellow pine, especially when set in the South, should be treated throughout the entire length of the pole, because the sap in such poles decays very readily, even above the ground line. I may say further that the brush treatment is not well adapted to timber which may be subjected to wear from abrasion. If railroad ties were given a treatment as superficial as the brush treatment of poles they would show almost no increase in life, because the portion penetrated with the preservative would be worn away very rapidly. Hence, one should bear in mind that, while brush and open-tank butt treatments give excellent results on telephone poles made from durable species of wood, these methods of treatment are not adapted to poles or timbers made from non-durable woods, nor are they adapted to those forms of timber subjected to wear, abrasion, etc.

One other point which I have in mind concerns the life of green versus air-seasoned poles. The paper under consideration brought out the point that untreated seasoned poles do not last any longer than those set green. This has been our experience with other forms of timber where accurate records have been kept. It is contrary to some of the older theories, but now that we have accurate records on many of these service tests we find that there is practically no advantage to be derived from seasoning, not only poles, but ties, fence posts, and other forms of timber. In fact, if the timber is held for an undue length of time it may deteriorate and a shorter length of life may be obtained.

C. A. Hobein, Jr.: I want to ask one question about the experience with cypress poles. I recently visited a railroad property in the state of Iowa. They used cypress poles and their experience has been very unfortunate. I inquired whether they had used the brush treatment, and it seemed they had used the brush treatment on the butts of these poles but they did not seem to feel it had done much good. The poles had been in the ground only a few years and they had practically all to be replaced. 
L. B. Cherry: Has any one noticed any difference in the decay of the poles that carried reasonably high potential currents, due to the leakage of the insulators and grounding of the current through the moist wood?

N. W. Storer: Are the poles impregnated in vacuum? Perhaps Mr. Hosford can tell us a little about that.

L. B. Cherry: I desire to ask another question, in regard to the green poles and the dry poles. When the dry poles were impregnated were they thoroughly dried, or was the moisture that was natural in the wood, in the atmosphere, sufficient to affect the impregnation? It seems to me that the theory of the matter would be this - the reason a green pole should last longer than the treated poles which were dry when treated, was that the moisture which was already in the green pole, the sap, was in a way of the same material as the wood itself, while when it was dried and put in the ground, it would absorb the moisture from the earth and an electrolytic action would set up in the fibre of the wood.

R. F. Hosford: First, with reference to Dr. von Schrenk's question about where and how decay was found to occur. Taking all the experimental groups, the brush treated poles are those we have had the best opportunity to study. The typical form of change is the one which we have illustrated in the paper. This typical form has been found in practically every case where we could determine how decay began. The only exceptions are two or three cases that are mentioned on one of the pages relating to analyses. You will find there that we saw two or three poles where direct disintegration of the treated layer had occurred. That is rather rare, and we have gone far enough in getting decay started on brush treated poles to be safe in saying that is not a typical form of change.

We do not know so much about where and how open tank. poles begin to decay.

Herman von Schrenk: In this Table VII referring to the Montgomery-New Orleans line you give the number of pieces in line decayed to the point of reconstruction, 75. Were those all brush treated?

R. F. Hosford: No. That table does not refer to brush treatment. That is a pressure treated line.

Herman von Schrenk: What is the significance of the word decay, as used in that connection?

R. F. Hosford: We are using the term decay, in the tables, as covering all types of disintegration whether the change actually occurred through insect attack or through the action of fungus growth. For simplicity in tabulation and to indicate how long the pole may be expected to last, we have taken the word decay and given it that meaning.

In a large number of cases with the pressure treated poles the decay has started in the untreated interior core. It is possible in a few cases, although we have not got enough evidence so 
that we can be sure about it, that the gradual loss of preservative from the pole has occurred to such an extent that the amount of preservative remaining in the pole is so low that it perhaps cannot longer prevent the inauguration of decay.

Herman von Schrenk: Decay in the interior?

R. F. Hosford: No. Decay of the kind I have just been speaking of would begin on the exterior surface. You will notice, however, from the discussion of the causes of the beginning of decay in the two tables relating to pressure treated poles that the only important cause for the beginning of decay that we have been able to locate is referred to as checks or shakes. Checks or shakes would, of course, allow decay to start through exposing the untreated interior section of the pole.

With reference to the question concerning longer life for open tank and pressure treated poles, either of these two processes give a longer life than brush treatment. The experiments that we are describing cover essentially a scale of intensity of treatment. The results, as we expected when we began, vary with the intensity. Of course, the variations in the weather conditions, in the exposure, whether northern or southern, have also some influence upon length of life.

With reference to the names of the proprietary compounds given letter designations in the paper, I might say that the nomenclature in detail for all of these cases will be found in some of the publications referred to in the bibliography. We were not inclined to go into the matter of dealing with them by name in this paper because the conclusion we reach and follow in our practise is that dead oil of coal tar is better than these more expensive compounds. We point out that dead oil of tar has done as well as the proprietary compounds.

Relative to the analysis of the oils extracted from poles, I would say that I know of no case where we have segregated the treated part of a cross-section from the untreated part and analyzed the two separately. As a matter of fact, the last analyses recorded in this paper were from samples taken as far back as 1909. We are in a position now to select a number of samples much more intelligently, which may enable us to elucidate some of the questions that are now open.

As to Dr. von Schrenk's last question with respect to heavy treatment versus light treatment, so far as I am aware, there is no current tendency towards treatment to refusal, which is the technical name for putting in as much as the timber will receive. What we are aiming to produce so far as our practise is concerned is to get our treatment, for example one of $12 \mathrm{lb}$. per cu. $\mathrm{ft}$., more uniformly distributed through the pieces we have to treat, as indicated in the paper. A large number of pieces of any timber that is to be creosoted must be put in the cylinder at the same time. There are records in the case of certain studies which show that if no attention is paid to the selection of the pieces before treatment-say that they were all placed in the cylinder just as 
they come-we would get widely varying results between different individual pieces when the lot is taken out. Our principal aim at present is to get the selected standard for the treatment realized in all the pieces or to get somewhere near to it. The indications are, from an examination of the poles treated by the pressure method 16 and 18 years ago, that we got treatments on certain individual pieces a long way out of balance with the average, and the paper has attempted to bring that fact out.

With reference to Mr. Teesdale's question and discussion I will say that we have attempted to emphasize the feature that he has also spoken about-the necessity of treating the upper parts of non-durable timber. We have endeavored in the paper to make this a means of distinction in the choice of methods to be employed in treating poles. Of course, it is true that the farther north you go the less obvious is the deterioration on the upper parts of poles. In the south, disregarding at least the sections of a pine pole which are heavily impregnated with rosin through "boxing" for turpentine, you will not find that any part of a pine pole will last very long, not even the heart of it.

I am glad that we drew from Mr. Teesdale the statement that the results obtained with poles with respect to the influence of seasoning is not unique and that it is true not only for poles but for other articles made from timber, that seasoning is not a very important means for increasing their life.

In answer to Mr. Hobein's question about cypress, the characteristics of cypress are about as follows: In the southern part of the territory in which cypress grows you can get varieties which are called in the trade, the red and the black cypress. The heart wood of these varieties is durable against decay. The sap wood decays rapidly, and decay of the sap wood has the further objection from the pole user's standpoint in that it occurs pretty evenly all the way up to the top of the pole. I have actually laid hands on cypress poles and found it possible to peel off a piece of decayed sap wood several feet long as you might take a piece of birch bark off a birch tree. There are varieties of cypress growing mainly in more northern latitudes known to the trade as the white and the yellow. Such information as we have indicates that not even the heart wood of these varieties is durable. I should say that most of our northern pole users would balk at using even the red or black varieties since the sap wood is not durable and breaks away from the pole in irregular fashion making the looks of the pole rather bad after it has been up for a little while. I have heard this objection as to the condition of the sap wood raised in connection with an experience with cypress in southern Michigan.

The better results obtained in wet locations are, I think, analogous to the common experience with all poles. Decay needs for starting, food,-which is in the pole-and air and moisture. If you immerse a pole in water or set it in swampy ground, which is pretty nearly equivalent to immersing it in 
water, you exclude the air from the surfaces in contact with the soil. If you set a pole in a rock hole and use a few large pieces of rock to wedge it in place so that the pole surfaces are pretty thoroughly ventilated, the free access of air brings about a relatively rapid evaporation of water from the pole surface so that the moisture content is kept relatively low. In either of these cases, swampy ground or the open rock hole, the nearly complete exclusion of one of the elements needed for the life of the fungus substantially retards decay and thereby increases durability. However, neither of these two conditions for setting poles are encountered frequently in actual practise, so that their influence in increasing the life of poles is accidental.

With respect to Mr. Cherry's question about the effect of grounding, I would say that I do not believe that in the case of these poles the question of current comes into the matter at all.

The discussion of green and seasoned poles relates entirely to poles that are untreated, that is, it is not a question of green versus treated poles, but green versus seasoned poles, both of them untreated. A treated pole lasts much longer than either a green or a seasoned pole, even in the case of brush treatment, which gives the lowest increase in life.

With respect to Mr. Storer's question, I would say that the brush treatment is applied by hand with a brush. It simply depends on the absorptive qualities of the wood and the very slight pressure applied to its surface for the liquid to make its way into the timber. You take care to see that the pole is dry -it must be dry if you want to get any oil into the timber. If it has been wet by rain and has not been given an opportunity to dry off, you will not get much absorption. The open tank treatment operates by creating a vacuum in the cells of the timber through which the preservative is drawn in when the treating bath is allowed to cool. In the pressure treatment we use a vacuum on practically all of our work because we usually start with a pole that is green or only slightly seasoned. We first steam the piece thoroughly to get the effect of seasoning in the way of volatilizing, dissolving, and driving out the water and the sap. We then finish the work analogous to air seasoning, by applying a vacuum which dries out the timber. We subsequently apply the preservative oil under pressure to force it into the cells of the timber. The function of the vacuum is mainly to assist in completing the seasoning preparatory to the application of the preservtive. It is true that in some processes the vacuum is used to help in the impregnation, but this practise is not common. 